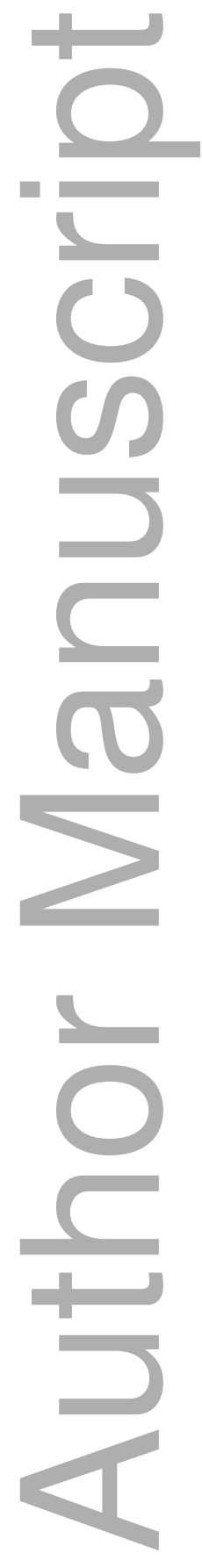

This is the author manuscript accepted for publication and has undergone full peer review but has not been through the copyediting, typesetting, pagination and proofreading process, which may lead to differences between this version and the Version of Record. Please cite this article as doi: $\underline{10.1111 / \text { caje. } 12216}$

This article is protected by copyright. All rights reserved 


\title{
Public-private Mix of Health Expenditure: A Political Economy and Quantitative Analysis
}

\author{
Shuyun May Li University of Melbourne \\ Solmaz Moslehi \\ Siew Ling Yew Monash University
}

Abstract. This paper constructs a simple model to examine decisions on public and private health spending under majority voting. In the model, agents with heterogeneous incomes choose how much to consume and spend on health care and vote for public health expenditure. The health status of an agent is determined by a CES composite of public and private health expenditure. The existence and uniqueness of the voting equilibrium are established. A quantitative exercise reveals the importance of the relative effectiveness of public and private health expenditure and their substitutability in determining the public-private mix of health expenditure and in accounting for the observed differences across a sample of 22 advanced democratic countries.

JEL classification: D7, H51, I1

Corresponding author: Siew Ling Yew, siew.ling.yew@monash.edu

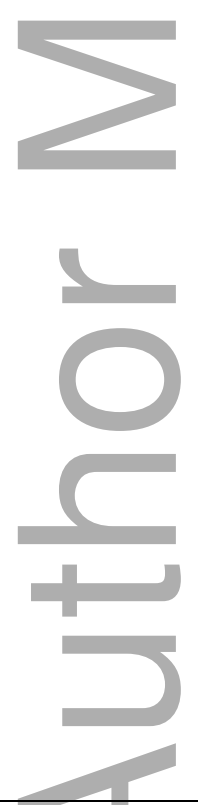

Acknowledgments. We would like to give special thanks to the editor, an anonymous referee and Chris Edmond for their valuable comments that have greatly improved the paper. We also give thanks to Pedro Gomis-Porqueras, Bruce Preston, Lawrence Uren, Jakob Madsen, Lata Gangadharan, Vai-Lam Mui and seminar participants at University of Melbourne, Monash University, Deakin University, University of New South Wales, Australian National University, Tsinghua University, Treasury of the New Zealand, PET Conference 2012, Southern Workshop in Macroeconomics 2012, the 11th Annual Canadian Health Economists' Study Group 2012, University of Graz, University of Queensland and Australiasian Public Choice Conference 2013, for their helpful comments. 


\section{Introduction}

Achieving a good health status in the overall population is one of the most important goals in every society. There are various factors that can improve health status. Among those most important factors are public and private expenditure on health care. The former includes expenditure on public health programs that provide public hospitals, immunization, disease control and diagnostic health screening, invest in new medical facilities and promote healthy environment through, e.g., reducing air and water pollutions. The latter refers to private expenditure on healthy food, vitamins and preventive and diagnostic health screenings, etc.

Although the total spending on public and private health care has been rising and consequently the overall health status has been improving in most countries, there are considerable differences in the mixture of public and private health spending over time and across countries. For instance, the share of public in total health expenditure has increased by more than $10 \%$ since the 1970s in the U.S., Austria, Greece and Japan, while it has decreased by more than $10 \%$ in Czech Republic, Norway and the U.K.. Across OECD countries, the share of public health expenditure ranges from less than $50 \%$ (e.g., the U.S.) to more than 80\% (e.g., Denmark, Norway, Sweden, Japan, the U.K., Czech Republic) in the 2000s.

Rapid population aging in OECD countries, partly due to the improvement in health status, has caused the financing of health care a major challenge. Many countries are undertaking or considering reforms to their health care systems. Understanding the interaction between public and private health care and how the existing public-private mix of health expenditure is determined can help policy makers design or reform health care policies to achieve the best outcome. This paper aims to explore how the public-private mix of health expenditure is determined collectively by people in a democratic society and what factors might be important in accounting for the observed cross-country differences.

We construct a simple static model to study how public and private health spending are determined by utility-maximizing agents with heterogeneous incomes through majority voting and how their decisions are shaped by various preference, economic and institutional factors. These factors include a preference parameter indicating how much people care about their health status, income distribution, the relative effectiveness of public and private health spending in improving the health status of a society and the degree of substitutability between public and private health spending.

In the model, agents receive exogenous heterogeneous incomes, decide upon how much to consume and to spend on health care and vote for the income tax to be used to finance public health expenditure. They have logarithmic utility function of consumption and health status which is a CES function of the public and private health expenditure. We establish the existence and uniqueness of the voting equilibrium, derive the closed form solution for the equilibrium majority choice of tax rate which is the preferred tax rate of the voter with median income, and also characterize some comparative static properties of the model. In particular, we find a positive relationship between the majority choice of tax rate and the degree of income inequality, consistent with a large literature that models majority voting over tax rate (e.g., see Meltzer and Richard 1981; Krusell and Rios-Rull 1999). ${ }^{1}$ We

\footnotetext{
${ }^{1}$ Meltzer and Richard (1981) model majority voting over the size of government, measured by an income tax rate used for financing redistributive transfers. Krusell and Rios-Rull (1999) develop a dynamic version of Meltzer and Richard (1981). Our study follows this literature by looking at majority voting over the size
} 
then discuss two extensions of the benchmark model. The first extension considers general utility and health production functions which satisfy standard assumptions. The second extension extends the static model to a dynamic setting with two-period lived agents in which survival probabilities of agents are endogenously determined by their health status. In both extensions, we establish the existence and uniqueness of a voting equilibrium which is the preferred tax rate of the median voter as well as the major comparative static properties of the benchmark model, under certain conditions. Finally, we calibrate the benchmark model and conduct a quantitative exercise to investigate how well the model may explain the observed differences in the mixture of health expenditure across a group of 22 advanced democratic OECD countries.

In the quantitative exercise, the baseline values for the parameters are calibrated to a few moments of the Canadian data that capture the relative size and composition of health expenditure in Canada. The sensitivity analysis suggests that the size of public health spending relative to national income and the share of public in total health expenditure are quite sensitive to the parameters in the CES health technology that indicate the relative effectiveness of public and private health spending and the degree of substitutability between these two. We further infer the values of these two parameters for each country using country-specific data moments and compute the model implied shares of public health expenditure for each country in the sample. The results show that the model implied mixture of health expenditure matches the data fairly well for the majority of countries, with an overall correlation of 0.65 between the computed shares of public health expenditure and their data counterparts.

The contributions of this paper are two-fold. The first contribution is a theoretical one. Our paper is one of the few studies that aim to explain the mixture of public and private expenditure on health care. Our work is related to a theoretical literature on the coexistence of private and public provision of health care, e.g., see Epple and Romano (1996) and Gouveia (1997). Following the strand of literature on the socialization of commodities, these studies focus on the public provision of a private good-health care-through majority voting in a static micro-theoretic context where private and public health care are treated as perfect substitutes. Our model also uses a voting mechanism to study the public and private mix of health expenditure which allows for general substitutability between these two, and we obtain some interesting and robust analytical results. ${ }^{2}$

There are some other political economy models on health expenditure. Lahiri and Richardson (2008) develop an overlapping generations model that is similar to our model in the second extension in which individuals vote on the division of tax revenues between public health spending and a lump sum transfer. Their focus, however, is on how public and private health spending impact on wealth inequality. Bethencourt and Galasso (2008) also present a political economy model that incorporates both public and private health spending to address the political complementarities between public health and social security. Another political economy model by Kifmann (2005) focuses on explaining the existence of public health insurance system in the absence of complete markets to insure against income risks.

of public health spending relative to GDP which also serves a redistributive role. In our model, the voting outcome also determines the mixture of public and private health spending through the interaction between them as specified by the CES health technology.

${ }^{2}$ Our focus is on the public and private expenditure on health care, rather than the public and private provision of health care, although these two are closely linked. 
The second contribution is a quantitative one. The aforementioned literature on health is largely purely theoretical. Our paper provides the first quantitative study on the publicprivate mix of health expenditure. ${ }^{3}$ We identify several important factors for the size and composition of health expenditure, in particular, the substitutability between public and private health spending $(\rho)$ and their relative effectiveness in improving health status $\left(\phi_{H}\right)$. We interpret these two factors as a reduced form representation of the interaction between public and private health care within a particular health care system, which is a complex issue that is affected by various political, demographical, institutional and economic factors. Our quantitative exercise provides a way to estimate the values of these two factors that are not easily observed in the data. Under the estimated values, there is a close match between the model implied mixture of public and private health expenditure and the data for the majority of the advanced democratic countries in our sample.

Knowing about the interaction between public and private health care is important for discussions concerning the design or reform of health care policies that aim to achieve efficiency and equity in health care. We illustrate this by using our estimates for $\rho$ and $\phi_{H}$, as a reduced form representation of the public-private interaction, to run two experiments. In the first experiment, we consider a reduction in public health spending, which is often recommended in health care reforms to ease budgetary burdens and show that different public-private interactions in health care systems, as indicated by different values for $\rho$ and $\phi_{H}$, can lead to very different health outcomes. In the second experiment, we show that a large fraction of differences in health inequality across countries can be accounted for by differences in the way public and private health care interact.

Further, our estimates suggest that for the majority of countries in the sample either a Cobb-Douglas form or a linear form is a reasonable approximation for the health technology. These results could be utilized in future empirical or quantitative research, as existing empirical literature has largely ignored the interaction between public and private health care due to its complexity. Although we are not able to directly compare our results with existing studies, there are some country-specific empirical studies or policy discussions that provide empirical support for our estimates. For example, our estimates imply that public and private health spending are complementary in the U.K. and highly substitutable in the U.S.. This is consistent with the empirical findings in Propper (2000), Cutler and Gruber (1996, 1996b) and Gruber and Simon (2008). The complementary relationship between public and private health spending for Denmark and Australia is also in line with the discussions on health care systems in Olejaz, Juul, Rudkjøbing, Birk and Krasnik (2012; OJRBK) and Chernichovsky (2000).

The rest of the paper proceeds as follows. Section 2 describes the model and establishes the analytical results. Section 3 discusses two extensions of the model. Section 4 presents the quantitative exercise. Section 5 concludes and briefly discusses some other important factors the model abstracts from.

\footnotetext{
${ }^{3}$ Our study belongs to an emerging quantitative literature on health related issues, such as De Nardi, French and Jones (2010), Jung and Tran (2010) and Hsu and Lee (2013). None of them, however, focuses on the public-private mix of health expenditure.
} 


\section{The Model}

In this section, we first describe the environment of the model economy, then solve the individuals' optimization problem, and finally characterize the majority voting equilibrium. All proofs are provided in Appendix A.

\subsection{The Environment}

The economy is populated with a large number of agents who receive exogenous incomes, make decisions on their consumption and private health spending and vote for taxes that finance public health expenditure. Agents are differentiated by their private incomes, $y_{i}$, which are independently drawn from an exogenous income distribution $F(\cdot)$, where $i$ refers to the $i$ th agent.

The utility of agent $i$ is defined over her consumption, $c_{i}$, and her health status, $X_{i}$ :

$$
U_{i}=\ln \left(c_{i}\right)+\gamma \ln \left(X_{i}\right),
$$

where $\gamma$ is the utility weight attached to health status and it reflects agents' taste for health relative to consumption. Health status is defined as a CES function of public and private health expenditure: ${ }^{4}$

$$
X_{i}=\left(\phi_{H} H^{\rho}+\phi_{h} h_{i}^{\rho}\right)^{1 / \rho},
$$

where $H$ denotes per capita public health expenditure and $h_{i}$ denotes agent $i$ 's private health expenditure. The parameters $\phi_{H} \in(0,1)$ and $\phi_{h} \equiv 1-\phi_{H}$ indicate the effectiveness of public and private health expenditure in improving health status, respectively. Parameter $\rho \in[0,1)$ measures the elasticity of substitution between public and private health expenditure, which is a constant given by $\varepsilon \equiv 1 /(1-\rho)$. The restriction that $\rho \in[0,1)$ is needed to establish some analytical results in Section 2.2 and 2.3. It implies that public and private health spending are substitutable in improving individuals' health status, with the elasticity of substitution $\varepsilon \in[1, \infty)$. When $\rho=0(\varepsilon=1)$, the health technology in (2) reduces to the Cobb-Douglas form and when $\rho$ approaches 1 ( $\varepsilon$ approaches $\infty$ ), it can be approximated by a linear form and public and private health spending are close to be perfectly substitutable.

The health technology specified in (2) is a reduced form representation of the functioning of public and private health care in a society. In practice, the structure of a health care system is shaped by various political, demographical, institutional and economic factors. Differences in any of these factors can give rise to different structures and roles of public and private health care in the overall system. As a consequence, the interaction of public and private health care and how they combine to affect the health status of a society are complex issues. Endogenizing such interaction is beyond the scope of this paper. Instead, we use the reducedform health technology in (2) to capture the contributions of private and public health spending in improving people's health status. This form allows for different effectiveness of public and private health spending as well as a general degree of substitutability between these two. When the parameters $\rho$ and $\phi_{H}$ are calibrated for each country in the quantitative

\footnotetext{
${ }^{4}$ In their specification of health technology, Bhattacharya and Qiao (2007) and Gupta and Vermeulen (2010) consider a complementary relationship between private and public health expenditure.
} 
analysis, the different values reflect differences in the underlying factors that form each country's health care systems.

Agent $i$ draws income $y_{i}$ from the exogenous distribution, pays income taxes at a uniform rate $\tau$ and divides her disposable income into consumption and private health spending. The budget constraint of agent $i$ is given by

$$
c_{i}+h_{i}=(1-\tau) y_{i}
$$

Public health expenditure, $H$, is financed by income taxes. Government budget is balanced:

$$
H=\tau \bar{y},
$$

where $\bar{y}$ is average income, i.e., $\bar{y} \equiv \int y d F(y)$. The tax rate is endogenously determined by a majority voting mechanism. That is, each agent votes on her preferred tax rate and the collective choice of the tax rate, $\tau$, is determined by the majority rule.

\subsection{Individual's Optimization for a Given Tax Rate}

Taking as given $\tau<1, y_{i}$ and $\bar{y}$, agent $i$ 's utility maximization problem is to choose $c_{i}$ and $h_{i}$ to maximize (1) subject to (2), (3) and (4). Equivalently, agent $i$ chooses $h_{i}$ to maximize

$$
U_{i}=\ln \left[(1-\tau) y_{i}-h_{i}\right]+\gamma \ln \left[\left(\phi_{H} H^{\rho}+\phi_{h} h_{i}^{\rho}\right)^{1 / \rho}\right] .
$$

It is easy to show that with $\rho \in[0,1)$ the utility function in $(5)$ is strictly concave in $h_{i}$ and satisfies the Inada condition. Thus, the individual's optimization problem has a unique interior solution that satisfies the first-order condition:

$$
\left[\phi_{H} H^{\rho}+\phi_{h} h_{i}^{\rho}\right] h_{i}^{1-\rho}=\gamma \phi_{h}\left[(1-\tau) y_{i}-h_{i}\right]
$$

where $H=\tau \bar{y}$. Note that (6) implicitly determines the unique and strictly positive optimal private health spending of agent $i$ as a function of $y_{i}, \tau, \bar{y}, \gamma, \phi_{H}$ and $\rho$. To simplify notation, we denote agent $i$ 's optimal private health spending as $h\left(y_{i} ; \tau\right)$, where $\tau$ is to be endogenized in the voting equilibrium.

From (6), we can obtain some interesting properties of the optimal private health expenditure, which are summarized in the proposition below.

PROPOSITION 1. Private health expenditure

(i) increases with private income: $\partial h / \partial y_{i}>0$, with income elasticity greater than one

(ii) decreases with income tax rate: $\partial h / \partial \tau<0$

(iii) decreases with average income: $\partial h / \partial \bar{y}<0$

(iv) decreases with the effectiveness of public health expenditure: $\partial h / \partial \phi_{H}<0$

(v) increases with the utility weight for health: $\partial h / \partial \gamma>0$

(vi) decreases (increases, does not change) with the elasticity of substitution between public and private health expenditure: $\partial h / \partial \rho<(>,=) 0$, if $h\left(y_{i} ; \tau\right) / H<(>,=) 1$.

(vii) increases by the same percentage when there are equal percentage increases in $y_{i}$ and $\bar{y}$ : $h$ is homogeneous of degree 1 in $y_{i}$ and $\bar{y}$. 
Part (i) implies that private health is a luxury good, as suggested by the empirical literature. ${ }^{5}$ Private health spending is also affected by income taxes that finance public health spending. The negative relationship between private health spending and income tax rate in part (ii) comes from two forces. First, a higher income tax rate reduces the disposable income. And second, a higher income tax rate leads to higher public health expenditure which crowds out private health expenditure, as private and public health expenditure are substitutable with $\rho \in[0,1)$. The intuition in the second force also applies to the result in (iii): a higher average income implies higher public health expenditure for a given tax rate which leads to lower private health expenditure. Intuitions for (iv) and (v) are straightforward.

Part (vi) suggests that a change in the substitutability between public and private health spending has different impacts on individuals with different initial private health spending. When an agent has lower (higher, the same) private health expenditure relative to per capita public health expenditure, she tends to decrease (increase, not change) her spending on private health when public and private health spending become more substitutable with a higher $\rho$. This result is reasonable: lower income people who typically have lower private health spending relative to public health spending tend to further reduce their private health spending when it becomes more substitutable with public health spending. The last result in (vii) implies that if an individual's private income and the national income both increase by $10 \%$, her optimal private health spending will also increase by $10 \%$. This result is in line with the properties in (i) and (iii) and it will be utilized later to help find the income elasticity of total health expenditure (see Section 4.1).

We have characterized the individual's problem for a given tax rate. Next, we characterize the preferred tax rate of each voter and the equilibrium tax rate under majority voting.

\subsection{The Majority Choice of Tax Rate}

The preferred tax rate of agent $i$ is the tax rate that maximizes her indirect utility $V_{i}$, with $V_{i}$ obtained by substituting out $X_{i}$ with $\left(\phi_{H}(\tau \bar{y})^{\rho}+\phi_{h}\left(h\left(y_{i} ; \tau\right)\right)^{\rho}\right)^{1 / \rho}$ in the utility function $(1)$ :

$$
V_{i}=\ln \left[(1-\tau) y_{i}-h\left(y_{i} ; \tau\right)\right]+\gamma \ln \left[\left(\phi_{H}(\tau \bar{y})^{\rho}+\phi_{h}\left(h\left(y_{i} ; \tau\right)\right)^{\rho}\right)^{1 / \rho}\right] .
$$

It can be shown that $\lim _{\tau \rightarrow 0}\left(\partial V_{i} / \partial \tau\right)=\infty$ and $V_{i}$ is strictly quasi-concave in $\tau$ (see the proof of Proposition 2 in Appendix A), thus there is a unique $\tau>0$ that maximizes $V_{i}$.

Applying the Envelope theorem to differentiate $V_{i}$ with respect to $\tau$ and then using (6), we obtain

$$
\frac{\partial V_{i}}{\partial \tau}=\frac{1}{\left[(1-\tau) y_{i}-h\left(y_{i} ; \tau\right)\right] \phi_{h}}\left[-\phi_{h} y_{i}+\phi_{H} \bar{y}\left(\frac{h\left(y_{i} ; \tau\right)}{\tau \bar{y}}\right)^{1-\rho}\right]
$$

Setting (8) to zero gives the equation that determines agent $i$ 's preferred tax rate, $\tau_{i}$ :

$$
\frac{h\left(y_{i} ; \tau_{i}\right)}{\tau_{i} \bar{y}}=\left(\frac{\phi_{h}}{\phi_{H}} \frac{y_{i}}{\bar{y}}\right)^{\frac{1}{1-\rho}}
$$

\footnotetext{
${ }^{5}$ Many empirical studies find a positive relationship between income and private health expenditure (see Feinstein 1993, for a review of the literature). Some studies also find that private health is a luxury good with income elasticity larger than one (see e.g., Scanlon 1980; Parker and Wong 1997).
} 
where $h\left(y_{i} ; \tau_{i}\right)$ is implicitly determined by (6) with $\tau=\tau_{i}$. Combining (6) and (9), we obtain the closed form solution for agent $i$ 's preferred tax rate:

$$
\tau_{i}=\frac{1}{\left(1+\frac{1}{\gamma}\right)\left[1+\left(\frac{\phi_{h}}{\phi_{H}}\right)^{\frac{1}{1-\rho}}\left(\frac{y_{i}}{\bar{y}}\right)^{\frac{\rho}{1-\rho}}\right]} .
$$

From (10), it is obvious that the preferred tax rates of agents are monotonically decreasing in their incomes: $\partial \tau_{i} / \partial y_{i}<0$. This negative relationship comes from the redistributive role of public health expenditure. Because agents receive the same benefit from public health spending regardless of their income levels while the contributions are proportional to their private incomes, agents with higher incomes would prefer lower tax rates.

As the choice of voters is over a single dimension-the income tax rate, to show the existence and uniqueness of a majority voting equilibrium, we need to show that the indirect utilities, as defined in (7), are single-peaked in tax rates. Proposition 2 establishes that the indirect utilities are strictly quasi-concave in tax rates such that the single-peakedness of voters' preferences holds. Further, the unique majority choice of the tax rate is simply the preferred tax rate of the median voter (the agent with median income), since the preferred tax rates are monotonically decreasing in voters' incomes.

PROPOSITION 2. There exists a unique voting equilibrium and the equilibrium tax rate, $\tau_{m}$, is the preferred tax rate of the voter with median income.

Therefore, the unique equilibrium tax rate under majority voting, $\tau_{m}$, is given by (10) with $i=m$. Note that $\tau_{m}$ represents the size of public health expenditure relative to national income. The ratio of median private health spending to per capita public health spending, $h\left(y_{m} ; \tau_{m}\right) / H_{m}$, is given by (9) with $i=m$, where $H_{m} \equiv \tau_{m} \bar{y}$ and $h\left(y_{m} ; \tau_{m}\right)$ is implicitly determined by (6) with $i=m$ and $\tau=\tau_{m}$.

It is easy to establish the comparative statics properties for $\tau_{m}$ and $h\left(y_{m} ; \tau_{m}\right) / H_{m}$. The equilibrium tax rate $\tau_{m}$ decreases with $y_{m} / \bar{y}$, increases with $\phi_{H}$ and $\gamma$ and does not vary with $\bar{y}$ if holding $y_{m} / \bar{y}$ unchanged. The negative relationship between $\tau_{m}$ and $y_{m} / \bar{y}$ implies that when income inequality is higher (lower $y_{m} / \bar{y}$ ), a majority of voters tend to favor a higher income tax rate or a higher level of public health spending relative to national income. This result is consistent with a large literature that models majority voting over tax rate; see Meltzer and Richard (1981) and Krusell and Rios-Rull (1999) for examples. In those models, tax revenues are used to finance some type(s) of redistributive expenditure such as transfers and pensions. In our model, public health, financed by tax revenues, also plays a redistributive role. The positive relationship of $\tau_{m}$ with $\phi_{H}$ and $\gamma$ are self-intuitive. We can also show using (10) with $i=m$ that $\tau_{m}$ increases (decreases, does not change) with $\rho$ when $\left(\phi_{h} / \phi_{H}\right)\left(y_{m} / \bar{y}\right)$ is less than (greater than, equal to) one, implying that when the relative effectiveness of private to public health spending $\left(\phi_{h} / \phi_{H}\right)$ is not too big such that $\left(\phi_{h} / \phi_{H}\right)\left(y_{m} / \bar{y}\right)$ is less than one $\left(y_{m} / \bar{y}\right.$ is typically less than one in the data), a majority of voters would prefer a higher level of public health expenditure when private and public health expenditure become more substitutable.

The comparative statics for $h\left(y_{m} ; \tau_{m}\right) / H_{m}$ are as follows: it increases with $y_{m} / \bar{y}$, does not change with $\gamma$, decreases with $\phi_{H}$ and decreases (increases, does not change) with $\rho$ when 
$\left(\phi_{h} / \phi_{H}\right)\left(y_{m} / \bar{y}\right)$ is less than (greater than, equal to) one. These properties are consistent with the comparative statics for $\tau_{m}$ and the intuitions described above also apply here.

It is difficult to derive analytical results regarding the public-private mix of health expenditure, which is represented by $\bar{h} / H_{m}$ or alternatively, $H_{m} /\left(H_{m}+\bar{h}\right)$, where $\bar{h}$ denotes the average private health expenditure across all agents. Instead, we conduct a quantitative analysis for a sample of advanced democratic countries in Section 4.

\section{Extensions of the Model}

In this section, we present two extensions of the benchmark model described above. In the first extension, we consider general functions for utility and health status which satisfy standard assumptions and explore the robustness of the major properties of the benchmark model with respect to the specific functional forms assumed. In the second extension, we extend the model to a dynamic setting with two-period lived agents in which the survival probabilities of agents enter the utility function as an effective discount factor and are endogenously determined by their health status. In the benchmark model, we put health status directly in the utility function without explicitly specifying why agents care about their health status.

\subsection{General Functions}

Assume a general utility function for an agent $i$ :

$$
U_{i}=u\left(c_{i}, X_{i}\right)
$$

where $u$ is strictly increasing and strictly concave in consumption and health status, satisfies the Inada condition, and is additively separable. Also define the health status of an agent $i$ as a general function of public and private health spending:

$$
X_{i}=X\left(h_{i}, H\right),
$$

where $H=\tau \bar{y}$ and $X$ is assumed to be strictly increasing and strictly concave in private and public health spending, satisfies the Inada conditions, and $\partial^{2} X / \partial h_{i} \partial H>0$. The CES function assumed for $X$ in the benchmark model satisfies all these assumptions.

The first-order condition with respect to $h_{i}$ is given by

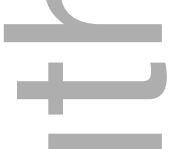

$$
\frac{\partial U_{i}}{\partial h_{i}}=-\frac{\partial u}{\partial c_{i}}+\frac{\partial u}{\partial X_{i}} \frac{\partial X}{\partial h_{i}}=0
$$

where $\partial X / \partial h_{i} \rightarrow \infty$ if $h_{i} \rightarrow 0$. It is easy to show the second derivative is negative. Thus, (13) determines a unique interior solution for the optimal private health spending, denoted

as $h\left(y_{i} ; \tau\right)$. Using the implicit function theorem, we can establish the comparative static results of the benchmark model under some additional conditions. Specifically, we show that $\partial h / \partial y_{i}>0$, and if $u$ is sufficiently concave and the elasticity of substitution between $h$ and $H$ in the health technology is sufficiently large, then we also have $\partial h / \partial \tau<0$ and $\partial h / \partial \bar{y}<0$ (see Appendix B for details).

The indirect utility of agent $i$ is given by

$$
V_{i}=u\left((1-\tau) y_{i}-h\left(y_{i} ; \tau\right), X\left(h\left(y_{i} ; \tau\right), H\right)\right) .
$$


Applying the Envelope theorem to differentiate $V_{i}$ with respect to $\tau$ and then substituting out $\partial u / \partial c_{i}$ using (13) gives

$$
\frac{\partial V_{i}}{\partial \tau}=\frac{\partial u}{\partial X_{i}}\left(-\frac{\partial X}{\partial h_{i}} y_{i}+\frac{\partial X}{\partial H} \bar{y}\right)
$$

Using (14), we show that $V_{i}$ is strictly quasi-concave in $\tau$ (see Appendix B) so that voters' preferences are single-peaked in $\tau$. Thus, a unique voting equilibrium exists, as in the benchmark model.

Setting $\partial V_{i} / \partial \tau$ in (14) to zero determines a unique interior $\tau$ that is agent $i$ 's preferred tax rate, denoted as $\tau_{i}$. It can be shown that $\tau_{i}$ decreases with $y_{i}$ under two conditions that $X$ is sufficiently less concave and the elasticity of substitution between $h$ and $H$ is sufficiently large (see Appendix B). When $X$ takes the CES form as in the benchmark model, both conditions hold if $\rho$ is close to one. With $\tau_{i}$ decreasing with $y_{i}$, the unique equilibrium tax rate is the preferred tax rate of the voter with median income, $\tau_{m}$, which is implicitly determined by

$$
-\frac{\partial X}{\partial h_{m}} y_{m}+\frac{\partial X}{\partial H} \bar{y}=0
$$

With general functions, we do not have a closed form solution for $\tau_{m}$. Nevertheless, (15) suggests that the majority choice of tax rate is affected by the interaction of public and private health spending in the health technology as well as income distribution of voters.

Given that $\partial \tau_{m} / \partial y_{m}<0$, we also have $\partial \tau_{m} / \partial\left(y_{m} / \bar{y}\right)<0$ if holding $\bar{y}$ unchanged. This result implies that for countries with the same average income, the majority choices of public health spending increase with their income inequalities (as measured by the inverse of $y_{m} / \bar{y}$ ).

In short, with three additional assumptions, namely, the utility function is sufficiently concave, the health status function is sufficiently less concave and the elasticity of substitution between public and private health spending is sufficiently large, the properties of the benchmark model still hold under general utility function and health technology.

\subsection{A Dynamic Setting}

Next, we briefly describe an extension of the benchmark model to a dynamic setting in which the survival probabilities of agents are endogenously determined by their health status. ${ }^{6}$ This extension is motivated by a large literature that incorporates health and endogenous mortality into a standard growth model to examine their implications for growth, poverty, inequality, and so on. ${ }^{7}$ In this literature, public health spending (or the tax rate used to finance it) is usually taken as exogenous. Also, most of the studies do not have disparities in health status or life expectancy across agents.

We consider an infinite-horizon overlapping generations economy that is populated with a large number of agents who potentially live for two periods: young and old adulthood.

\footnotetext{
${ }^{6} \mathrm{~A}$ more detailed description and characterization of the extended model as well as its quantitative implications can be found in the online working paper: http://solmaz.moslehi.me/Files/health_olg.pdf

${ }^{7}$ Most of this literature considers one type of health expenditure (Blackburn and Cipriani 2002; Chakraborty and Das 2005; Hall and Jones 2007; Chakraborty 2004; Áısa and Pueyo 2006). Only a few studies consider the roles of both public and private health expenditure, such as Zhang, Zhang and Leung (2006), Tang and Zhang (2007), Bhattacharya and Qiao (2007) and Gupta and Vermeulen (2010).
} 
In young adulthood, agents draw incomes $y_{i, t}$ from an exogenous income distribution $F_{t}(\cdot)$, consume, spend on private health, save for old age and vote for taxes that finance public health expenditure in period $t$. Each young adult gives birth to one offspring and thus the size of young population is constant. In old adulthood, agents consume what they have and exit the economy. Note that in this setup, all economic and political decisions are made in young adulthood and old adults have no incentive to vote.

Survival in young adulthood is certain, but survival in old adulthood is uncertain. A young adult $i$ 's survival probability to old adulthood, $p_{i, t} \in(0,1)$, is assumed to be a function of the health status acquired in young adulthood (a similar functional form for the probability of survival is assumed in Chakraborty (2004)):

$$
p_{i, t}=p\left(h_{i, t}, H_{t}\right)=\frac{X_{i, t}}{1+\kappa X_{i, t}}, \kappa>1
$$

where

$$
X_{i, t}=\left(\phi_{H} H_{t}^{\rho}+\phi_{h} h_{i, t}^{\rho}\right)^{1 / \rho}, H_{t}=\tau_{t} \bar{y}_{t} .
$$

The lifetime utility of a young adult in period $t$ is defined over her consumption in young adulthood, $c_{i, t}$, and consumption in old adulthood, $d_{i, t+1}$ (the utility from death is assumed to be zero):

$$
U_{i t}=\ln \left(c_{i, t}\right)+\beta p_{i, t} \ln \left(d_{i, t+1}\right),
$$

where $\beta \in(0,1)$ is the subjective discount factor. The budget constraints of agent $i$ in young and old adulthood, respectively, are given by:

$$
\begin{aligned}
c_{i, t}+s_{i, t}+h_{i, t} & =\left(1-\tau_{t}\right) y_{i, t} \\
d_{i, t+1} & =R_{t+1} s_{i, t}
\end{aligned}
$$

where $R_{t+1}$ denotes the gross rate of return on private savings. To deal with the mortality risk, we follow the strand of literature (e.g., Chakraborty 2004) that assumes a perfectly competitive annuities market for private savings. That is, $R_{t+1}$ is given by $\left(1+r_{t+1}\right) / \bar{p}_{t}$, where $1+r_{t+1}$ is the exogenous gross interest rate and $\bar{p}_{t}$ is the average survival probability which is endogenized in equilibrium. ${ }^{8}$

Young adult $i$ 's optimization problem is to choose $c_{i, t}, d_{i, t+1}, h_{i, t}$ and $s_{i, t}$ to maximize (18) subject to (16), (17), (19) and (20), taking as given $R_{t+1}, \tau_{t}, y_{i, t}$ and $\bar{y}_{t}$. The first-order conditions (the second-order condition for a local maximum holds under certain condition) yield

$$
\frac{\left(1+\beta p_{i, t}\right) h_{i, t}^{1-\rho}}{\left(1-\tau_{t}\right) y_{i, t}-h_{i, t}}=\frac{\beta \phi_{h} X_{i, t}^{1-\rho}}{\left(1+\kappa X_{i, t}\right)^{2}} \ln \left(R_{t+1} \frac{\beta p_{i, t}}{1+\beta p_{i, t}}\left(\left(1-\tau_{t}\right) y_{i, t}-h_{i, t}\right)\right)
$$

which, combined with (16) and (17), implicitly determines young adult $i$ 's optimal private health spending as a function of $y_{i, t}, \tau_{t}, \bar{y}_{t}, R_{t+1}, \beta, \rho, \phi_{H}$ and $\kappa$. Again, for the ease of notation, we denote it as $h\left(y_{i, t} ; \tau_{t}\right)$ and the corresponding survival probability is then given by $p\left(h\left(y_{i, t} ; \tau_{t}\right), H_{t}\right)$.

\footnotetext{
${ }^{8}$ Individuals do not internalize the external effects of their decisions on the average survival probability and hence on the annuity return. As pointed out by Philipson and Becker (1998), ignoring this externality may lead to excessive health expenditure. There may exist other voting mechanisms that could mitigate this externality issue.
} 
Using (21), we can show: (i) $\partial h / \partial y_{i, t}>0$, (ii) $\partial h / \partial \tau_{t}<0$ (under some conditions), and (iii) $\partial p / \partial y_{i, t}>0$. Results (i) and (ii) are consistent with the benchmark model. Result (iii) follows from (i) and it is consistent with the positive effect of income on life expectancy found in the empirical literature (e.g., see Pritchett and Summers 1996; Cutler, Deaton and Lleras-Muney 2006).

Again, the preferred tax rate of young adult $i$, denoted as $\tau_{i, t}$, maximizes her indirect utility function and it is determined by a similar equation as in the benchmark model: ${ }^{9}$

$$
\frac{h\left(y_{i, t} ; \tau_{i, t}\right)}{\tau_{i, t} \bar{y}_{t}}=\left(\frac{\phi_{h}}{\phi_{H}} \frac{y_{i, t}}{\bar{y}_{t}}\right)^{\frac{1}{1-\rho}} .
$$

We show that the indirect utilities are strictly quasi-concave in tax rate, the preferred tax rate of a young adult, $\tau_{i, t}$, is unique, and further, $\partial \tau_{i, t} / \partial y_{i, t}<0$ under certain condition. Therefore, for a given $\bar{p}_{t}$ and hence a given $R_{t+1}$, there exists a unique majority choice of tax rate which is the preferred tax rate of the median voter, denoted as $\tau_{m, t}$. And $\tau_{m, t}$ is implicitly determined by $(22)$ with $i=m$, where $h\left(y_{m, t} ; \tau_{m, t}\right)$ is implicitly determined by (21), (16) and (17) with $i=m$ and $\tau_{t}=\tau_{m, t}$.

A voting equilibrium in period $t$ is characterized by a collection of $\bar{p}_{t}, \tau_{m, t}$ and $h\left(\cdot ; \tau_{m, t}\right)$ such that: (i) taking $\bar{p}_{t}$ and hence $R_{t+1} \equiv\left(1+r_{t+1}\right) / \bar{p}_{t}$ as given, $\tau_{m, t}$ is the unique majority choice of tax rate in period $t$ and hence $H_{m, t} \equiv \tau_{m, t} \bar{y}_{t}$ is the unique majority choice of public health expenditure in period $t$; (ii) taking $R_{t+1}$ and $\tau_{m, t}$ as given, the optimal private health spending of a young adult with income $y_{i, t}$ is given by $h\left(y_{i, t}, \tau_{m, t}\right)$, where $y_{i, t}$ is a random draw from the income distribution $F_{t}$; (iii) $\bar{p}_{t}$ is the average survival probability of young adults in period $t$, i.e., $\bar{p}_{t}=\int_{0}^{\infty} p\left(h\left(y ; \tau_{m, t}\right), H_{m, t}\right) d F_{t}(y)$. Notice that this model defines a mapping that maps an average survival probability into a new average survival probability, and the voting equilibrium corresponds to a fixed point of this mapping. In the online working paper, we provide a discussion on the existence and uniqueness of a voting equilibrium. Basically, we argue that the mapping is continuous, downward sloping, and above the 45 degree line for small average survival probabilities. These properties ensure the existence and uniqueness of a fixed point for average survival probability. In particular, the downward sloping property comes from a positive relationship between $R_{t+1}$ and public health spending as well as a positive relationship between $R_{t+1}$ and private health spending provided that the elasticity of substitution between public and private health spending is not too high. As a result, when $\bar{p}_{t}$ falls or $R_{t+1}$ increases, public and private health spending both increase such that individual survival probabilities increase, leading to a higher average survival probability.

If the exogenous income distributions $\left(F_{t}\right)$ converge to a stationary income distribution and the exogenous interest rates $\left(r_{t+1}\right)$ converge to a constant interest rate, the sequence of voting equilibria in every period will converge to a steady state voting equilibrium. ${ }^{10}$

Some of the comparative static properties of the benchmark model can also be established: (i) the equilibrium tax rate $\tau_{m, t}$ decreases and $h_{m, t} / H_{m, t}$ increases with $y_{m, t} / \bar{y}_{t}$, given $\bar{y}_{t}$; (ii)

\footnotetext{
${ }^{9}$ The similarity between (9) and (22) results from the use of a logarithmic utility function in both models as well as the specific functional form for the survival probabilities in the extended model.

${ }^{10}$ There are no connections across generations and hence no connections among the voting equilibria for every period. If $F_{t}$ and $r_{t+1}$ are constant over time, the voting equilibria for every period will be the same. Hence, there is no essential difference between the infinite-horizon overlapping generations setting and a two-period setting with only one generation of individuals.
} 
$h_{m, t} / H_{m, t}$ decreases with $\phi_{H}$; (iii) $h_{m, t} / H_{m, t}$ decreases (increases, does not change) with $\rho$ when $\left(\phi_{h} / \phi_{H}\right)\left(y_{m, t} / \bar{y}_{t}\right)$ is less than (greater than, equal to) one.

\section{Quantitative Exercise}

\subsection{Baseline Calibration}

In this section we conduct a quantitative exercise using the benchmark model. This requires specifying the exogenous income distribution and assigning values for parameters. We assume a log-normal income distribution with mean and standard deviation of the logarithm of income being $\mu$ and $\sigma$, respectively. ${ }^{11}$ Other parameters of the model include: the parameter measuring the weight attached to health in the utility function $(\gamma)$, the parameter measuring the relative effectiveness of public and private health in the CES health technology $\left(\phi_{H}\right.$, $\phi_{h}=1-\phi_{H}$ ) and the parameter measuring the degree of substitutability between public and private health spending $(\rho)$. In the baseline calibration, we calibrate these 5 parameters to match certain characteristics of the Canadian data in 2000s (2000-2009). Canada is chosen for its well-established universal public health care system as well as data availability.

First, the income distribution is calibrated to match the income distribution of Canadian households. That is, $\mu$ and $\sigma$ are calibrated to match the mean income, $\bar{y}$ and the income inequality measure, $y_{m} / \bar{y}$, for Canadian households. For Canada in 2000s, the average annual value of $\bar{y}$ is 34, 442.7 (PPP-based per capita GDP, constant 2005 international \$) according to World Development Indicator-2011 and the value of $y_{m} / \bar{y}$ is 0.8659 according to $O E C D$.Stat Extracts - 2011. Hence, the value of $\mu$ is given by $\mu=\ln \left(\bar{y} \cdot\left(y_{m} / \bar{y}\right)\right)=10.3031$ and the value of $\sigma$ is given by $\sigma=\sqrt{2 \ln \left(\bar{y} / y_{m}\right)}=0.5366$.

Parameters $\gamma, \rho$ and $\phi_{H}$ are not directly deducible from the data. We calibrate them jointly to match three moments of the Canadian data, using the three equations that characterize the equilibrium of the model, namely, (9), (6) and (10) with $i=m$. Denote $h_{m} \equiv h\left(y_{m} ; \tau_{m}\right)$, these three equations are explicitly given by

$$
\begin{aligned}
& \frac{h_{m}}{H_{m}}=\left(\frac{\phi_{h}}{\phi_{H}} \frac{y_{m}}{\bar{y}}\right)^{\frac{1}{1-\rho}}, \\
& {\left[\phi_{H} H_{m}^{\rho}+\phi_{h} h_{m}^{\rho}\right] h_{m}^{1-\rho}=\gamma \phi_{h}\left[\left(1-\tau_{m}\right) y_{m}-h_{m}\right],} \\
& \tau_{m}=\frac{1}{\left(1+\frac{1}{\gamma}\right)\left[1+\left(\frac{\phi_{h}}{\phi_{H}}\right)^{\frac{1}{1-\rho}}\left(\frac{y_{m}}{\bar{y}}\right)^{\frac{\rho}{1-\rho}}\right]} .
\end{aligned}
$$

The first moment is the average annual ratio of public health expenditure to GDP, represented by $\tau_{m}=H_{m} / \bar{y}$ in the model, which is $6.83 \%$ for Canada in 2000s according to OECD Health Dataset - 2011. The second moment is the average annual share of public

\footnotetext{
${ }^{11} \mathrm{~A}$ log-normal income distribution is commonly assumed in both empirical and theoretical literature. For Canada, Brzozowski, Gervais, Klein and Suzuki (2010) find that log-normality is a reasonable approximation for disposable incomes. Some other empirical studies also find that income distributions are close to be lognormal in countries like the U.S., the U.K. and Japan (see e.g., Harrison 1981; Battistin, Blundell and Lewbel 2009; Nishino and Kakamu 2011).
} 
health expenditure in total health expenditure, $H_{m} /\left(H_{m}+\bar{h}\right) .{ }^{12}$ The value of this moment is $70.14 \%$ for Canada in 2000s according to OECD Health Dataset - 2011. The third moment is the average ratio of median to mean private health expenditure, $h_{m} / \bar{h}$, which is 0.6962 for Canada in 2000s according to National Household Survey from Statistics Canada. ${ }^{13}$ Note that these three moments capture the size of public health expenditure, the public-private mix of health expenditure and the inequality of private health expenditure, respectively.

Given the moments above, the ratio of median private health expenditure to per capita public health expenditure, $h_{m} / H_{m}$, appearing in (23) and (24), is obtained as $h_{m} / H_{m}=$ $\left(h_{m} / \bar{h}\right)\left(\bar{h} / H_{m}\right)$. Its data value is 0.2964 , suggesting that the median private health spending of Canadian households is slightly less than one third of the per capita public health spending.

The calibration of $\gamma, \rho$ and $\phi_{H}$ works as follows. First, note that we can solve $\phi_{H}$ and $\gamma$ from (23) and (24):

$$
\text { (3) } \phi_{H}=\frac{1}{1+\left(\frac{h_{m}}{H_{m}}\right)^{1-\rho} \frac{\bar{y}}{y_{m}}} \text { and } \gamma=\frac{\tau_{m} \frac{y_{m}}{h_{m}}+1}{\left(1-\tau_{m}\right) \frac{y_{m}}{h_{m}}-1}
$$

where $y_{m} / h_{m}$ is given by $\left(1 / \tau_{m}\right)\left(y_{m} / \bar{y}\right) /\left(h_{m} / H_{m}\right)$.

Therefore, given data values for the moments $\tau_{m}, y_{m} / \bar{y}$ and $h_{m} / H_{m}$, the calibration reduces down to finding the value of $\rho \in[0,1)$, to match the data value of $H_{m} /\left(H_{m}+\bar{h}\right)$. This is achieved by iterating on the values of $\rho$ until the computed value of $H_{m} /\left(H_{m}+\bar{h}\right)$ matches its data value. Here, $H_{m}$ is simply given by $\tau_{m} \bar{y}$ and $\bar{h}$ is computed by numerically evaluate the integral $\int_{0}^{\infty} h\left(y ; \tau_{m}\right) d F(y)$, where $h\left(y ; \tau_{m}\right)$ is the optimal private health spending function that is implicitly determined by (6) with $y_{i}=y$ and $\tau=\tau_{m}$ and $F(y)$ is now the cumulative distribution function of the log-normal income distribution with parameters $\mu$ and $\sigma$. We find the $\rho$ value that matches $H_{m} /\left(H_{m}+\bar{h}\right)$ exactly (error less than $10^{-5}$ ).

Table 1 summarizes the calibrated parameter values and the data moments used for calibration. The calibrated value of $\rho$ implies an elasticity of substitution between public and private health spending of 2.5183, suggesting that these two are substitutable to a relatively high degree. The value of $\phi_{H}$ is a bit higher than 0.5 , suggesting that public health spending is slightly more effective than private health spending in improving the society's health status. Due to the lack of relevant empirical or quantitative studies, we cannot compare the calibrated values for $\rho$ and $\phi_{H}$ with other studies. Nevertheless, these values seem realistic for the Canadian economy. Finally, the value of $\gamma$, which is the relative weight attached to health status in the utility function, is calibrated to be 0.1009 .

Based on 20,000 random income draws from the log-normal income distribution, Figure 1 plots the kernel density and cumulative distribution functions for income, consumption, private health expenditure, health status and elasticities of private health expenditures with

\footnotetext{
${ }^{12}$ Total health expenditure is defined by OECD Health Data 2011 as the sum of public and private health expenditure. Public health expenditure is health expenditure incurred by public funds and includes promoting health and preventing disease, curing illness, caring for persons require nursing care, publicly-financed gross capital formation in health facilities plus capital transfers to the private sector for hospital construction and equipment, expenditure on medical goods. Private health expenditure is the privately funded part of total health expenditure. Private sources of funds include out-of-pocket payments, private insurance programmes, charities and occupational health care.

${ }^{13}$ National Household Survey is purchased from Statistics Canada, available at: http://cansim2.statcan.gc.ca/
} 
TABLE 1

Baseline calibration

\begin{tabular}{lll}
\hline Parameters & Description & Calibrated value \\
\hline$\gamma$ & Utility weight attached to health status & 0.1009 \\
$\rho$ & Substitutability between public and private health expenditure & 0.6029 \\
$\phi_{H}$ & Effectiveness of public health expenditure in health production & 0.5839 \\
$\mu$ & Mean of the logarithm of income distribution & 10.3031 \\
$\sigma$ & Standard deviation of the logarithm of income distribution & 0.5366 \\
\hline Moments & Description & Data Value \\
\hline$\tau_{m}$ & Ratio of public health to GDP & $6.83 \%$ \\
$H_{m} /\left(H_{m}+\bar{h}\right)$ & Share of public health in total health expenditure & $70.14 \%$ \\
$h_{m} / \bar{h}$ & Ratio of median to mean private health expenditure & 0.6962 \\
$\bar{y}$ & GDP per capita (PPP measure) & $34,442.7$ \\
$y_{m} / \bar{y}$ & Ratio of median to mean income & 0.8659 \\
\hline
\end{tabular}
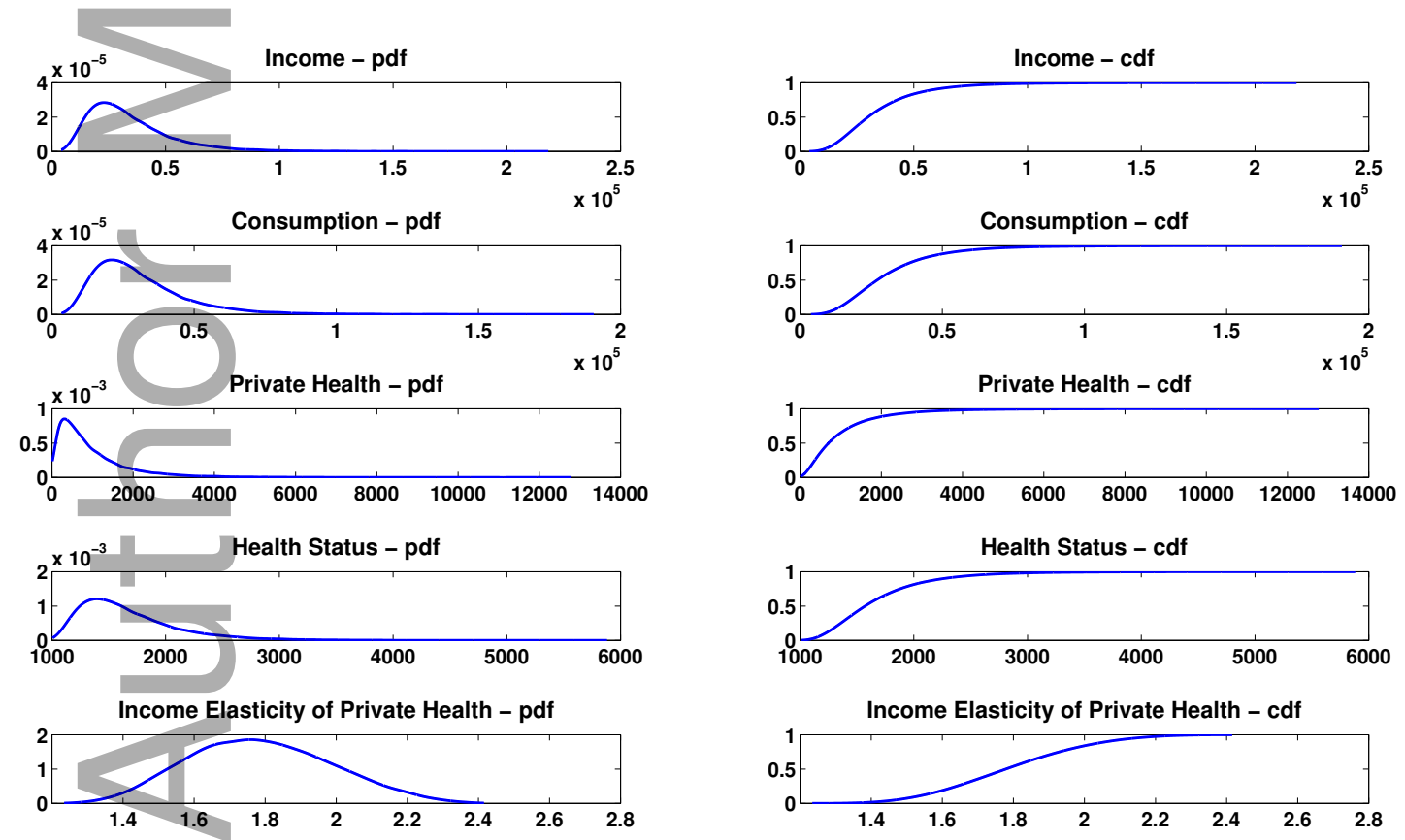

FIGURE 1 Kernel density and cumulative distribution functions 
respect to private incomes under the baseline calibration. ${ }^{14}$ First note that the income elasticities of private health expenditures are all greater than one (consistent with Proposition $1(\mathrm{i})$ ), with minimum, maximum and mean values given by $1.2344,2.4159$ and 1.7884 , respectively. Income elasticity of health spending has been an important subject addressed in the empirical literature. Our quantitative result is in line with findings of studies that look at private medical care like eyeglasses, plastic surgery and nursing home care and find that income elasticities of such private health expenditure are substantially greater than one (see e.g., Scanlon 1980; Parker and Wong 1997). With a log-normal income distribution, our model implies an elasticity of total health expenditure with respect to national income equal to $1 .{ }^{15}$ Most of the empirical studies find that the income elasticities of total health expenditures are around one or greater than one (see, e.g., Newhouse 1977; Gerdtham, Sogaard, Andersson and Jonsson 1992; Hitiris and Posnett 1992).

Another notable feature from Figure 1 is that the distribution of private health expenditure is much more skewed than the distribution of income, with a significant fraction of households having very little private health expenditure. This suggests that the inequality of private health spending is much higher than the inequality of income, as indicated by a ratio of median to mean private health expenditure $\left(h_{m} / \bar{h}=0.6962\right)$ that is lower than the ratio of median to mean income $\left(y_{m} / \bar{y}=0.8659\right)$. However, the distribution of health status is less skewed than the distribution of private health spending, because of the contribution of the universal public health spending.

\subsection{Sensitivity Analysis}

Next, we conduct a numerical exercise to investigate the sensitivity of endogenous variables to variations in the primitives of the model. Such analysis will help us identify important parameters for variations in a particular variable. The variables that are of interest include the ratio of public health expenditure to national income, $\tau_{m}$, the ratio of median private health expenditure to per capita public health expenditure, $h_{m} / H_{m}$ and the share of public health expenditure in total health expenditure, $H_{m} /\left(H_{m}+\bar{h}\right)$. We examine how these variables respond to variations in parameters $\gamma, \rho, \phi_{H}$ and $y_{m} / \bar{y}$. Like $\tau_{m}, h_{m} / H_{m}$ and $H_{m} /\left(H_{m}+\bar{h}\right)$ do not vary with $\bar{y}$ if holding $y_{m} / \bar{y}$ unchanged.

Baseline values for these parameters are given in Table 1 above. We consider 5, 10 and $15 \%$ variations of each parameter around its baseline value, with all other parameters kept at their baseline values. For each variation, $h_{m} / H_{m}$ is given by (23) and $\tau_{m}$ is given by (25). To calculate $H_{m} /\left(H_{m}+\bar{h}\right)$, we follow the same procedure as described in the baseline

\footnotetext{
${ }^{14}$ For each income draw $y_{i}$, the corresponding private health spending $h\left(y_{i} ; \tau_{m}\right)$ is numerically solved from (6) and the-corresponding consumption and health status are also obtained. To calculate the individual income elasticities of private health spending, we use the analytical expression for $\left(\partial h / \partial y_{i}\right)\left(y_{i} / h\left(y_{i} ; \tau_{m}\right)\right)$ given in the proof of Proposition 1 (i) in Appendix A.

${ }^{15}$ From $(25), \tau_{m}$ does not vary with $\bar{y}$ if holding $y_{m} / \bar{y}$ unchanged, so the elasticity of $H_{m}$ with respect to $\bar{y}$ is 1. The elasticity of average private health spending $\bar{h}$ with respect to $\bar{y}$ is also 1 if holding $y_{m} / \bar{y}$ unchanged. This is because with a log-normal distribution, an increase in $\bar{y}$ with $y_{m} / \bar{y}$ unchanged will shift up the whole income distribution such that all income levels increase by the same pecentage as the increase in $\bar{y}$. This then leads to an increase in $\bar{h}$ by the same percentage, because private health expenditures are homogenous of degree 1 in $\bar{y}$ and private incomes (see Proposition 1 (vii)). Therefore, the elasticity of $H_{m}+\bar{h}$ with respect to $\bar{y}$ (holding $y_{m} / \bar{y}$ unchanged) is 1 .
} 
calibration to get $\bar{h}$ and $H_{m}$ equals the product of computed $\tau_{m}$ and $\bar{y}$.

Table 2 summarizes the results from the numerical exercise. First, note that the analytical results regarding comparative static properties for $\tau_{m}$ and $h_{m} / H_{m}$ in Section 2.3 are all confirmed by the numerical results here. That is, $\tau_{m}$ increases with $\gamma$ and $\phi_{H}$ and decreases with $y_{m} / \bar{y}$; and $h_{m} / H_{m}$ does not vary with $\gamma$, decreases with $\phi_{H}$ and increases with $y_{m} / \bar{y}$. In particular, under the baseline calibration $\left(\phi_{h} / \phi_{H}\right)\left(y_{m} / \bar{y}\right)=0.6170<1$, such that $\tau_{m}$ increases with $\rho$ while $h_{m} / H_{m}$ decreases with $\rho$. In terms of the magnitude of changes, $\tau_{m}$ is most sensitive to variations in $\phi_{H}$ and $\gamma$ and also sensitive to variations in $\rho$ and $y_{m} / \bar{y}$. And $h_{m} / H_{m}$ is most sensitive to $\phi_{H}$ and also very sensitive to variations in $\rho$ and $y_{m} / \bar{y}$.

Consistent with the comparative statics for $\tau_{m}$, the share of public health expenditure in total health expenditure, $H_{m} /\left(H_{m}+\bar{h}\right)$, increases with $\gamma, \rho$ and $\phi_{H}$. However, it has no clear relationship with $y_{m} / \bar{y}$. It is quite sensitive to variations in $\rho$ and $\phi_{H}$, while not sensitive at all to variations in $\gamma$ and $y_{m} / \bar{y}$.

TABLE 2

Sensitivity of variables to parameters

\begin{tabular}{ccccc}
\hline \hline & $\gamma$ & $\rho$ & $\phi_{H}$ & $\frac{y_{m}}{\bar{y}}$ \\
\hline \hline$-15 \%$ & Majority choice of tax rate $\left(\tau_{m}\right)$ & \\
$-10 \%$ & 0.0589 & 0.0642 & 0.0500 & 0.0723 \\
$-5 \%$ & 0.0620 & 0.0654 & 0.0565 & 0.0710 \\
Baseline & 0.0652 & 0.0668 & 0.0627 & 0.0696 \\
$+5 \%$ & 0.0683 & 0.0683 & 0.0683 & 0.0683 \\
$+10 \%$ & 0.0714 & 0.0700 & 0.0732 & 0.0670 \\
$+15 \%$ & 0.0744 & 0.0719 & 0.0774 & 0.0657 \\
\hline Ratio of median private to per capita public health & expenditure $\left(h_{m} / H_{m}\right)$ \\
\hline$-15 \%$ & 0.0775 & 0.0740 & 0.0809 & 0.0644 \\
$-10 \%$ & 0.2964 & 0.3714 & 0.7219 & 0.1968 \\
$-5 \%$ & 0.2964 & 0.3479 & 0.5379 & 0.2273 \\
Baseline & 0.2964 & 0.3229 & 0.4000 & 0.2605 \\
$+5 \%$ & 0.2964 & 0.2964 & 0.2964 & 0.2964 \\
$+10 \%$ & 0.2964 & 0.2682 & 0.2182 & 0.3351 \\
$+15 \%$ & 0.2964 & 0.2384 & 0.1593 & 0.3768 \\
+ & 0.2964 & 0.2071 & 0.1149 & 0.4214 \\
\hline \hline Share of public in total health expenditure & $\left(H_{m} /\left(H_{m}+\bar{h}\right)\right)$ \\
\hline$-15 \%$ & 0.7010 & 0.6675 & 0.5182 & 0.7000 \\
$-10 \%$ & 0.7011 & 0.6777 & 0.5834 & 0.7007 \\
$-5 \%$ & 0.7013 & 0.6889 & 0.6448 & 0.7011 \\
Baseline & 0.7014 & 0.7014 & 0.7014 & 0.7014 \\
$+5 \%$ & 0.7016 & 0.7153 & 0.7525 & 0.7015 \\
$+10 \%$ & 0.7017 & 0.7306 & 0.7980 & 0.7015 \\
\hline \hline
\end{tabular}




\subsection{Cross-Country Analysis}

As described in the Introduction, there are considerable differences in the mixture of public and private health expenditure across OECD countries. The sensitivity results above suggest that this mixture is very sensitive to variations in $\rho$ and $\phi_{H}$ but not to other parameters. ${ }^{16}$ So, we next conduct a quantitative exercise to examine whether the observed differences in the public-private mix of health expenditure can be accounted for by variations in $\rho$ and $\phi_{H}$ for a sample of 22 OECD countries with the highest index of democracy. ${ }^{17}$ These countries have relatively similar economic and political backgrounds.

There are some difficulties in conducting this quantitative exercise. First, there are no empirical or quantitative studies that would give us values of $\rho$ and $\phi_{H}$ for each country in our sample so that we can use them to compute the model predicted $H_{m} /\left(H_{m}+\bar{h}\right)$ values for each country and compare them with their data counterparts. Second, unlike Canada, we do not have data that would allow us to calculate moments like $h_{m} / \bar{h}$ or $h_{m} / H_{m}$ so that we can use them (together with $\tau_{m}$ ) to calibrate the values of $\rho$ and $\phi_{H}$ for each country and then compute the model predicted $H_{m} /\left(H_{m}+\bar{h}\right)$ values.

Therefore, we will do a fitting exercise whereby the values of $\rho$ and $\phi_{H}$ for each country are chosen such that the size of public expenditure relative to national income $\left(\tau_{m}\right)$ and the mixture of public and private health expenditure $\left(H_{m} /\left(H_{m}+\bar{h}\right)\right)$ are matched with the data as close as possible. ${ }^{18}$ That is, we keep $\gamma$ at its baseline value for all countries and use country-specific values for $y_{m} / \bar{y}$ and $\bar{y}$ (data obtained from OECD. Stat Extracts - 2011 and World Development Indicator-2011, respectively) to calibrate the country-specific log-normal income distributions and find values of $\rho$ and $\phi_{H}$ for each country to minimize the distance between the model implied $\tau_{m}$ and $H_{m} /\left(H_{m}+\bar{h}\right)$ values and their corresponding data values. In defining the distance measure that is minimized, we give more weight to the distance between the computed $\tau_{m}$ and its data counterpart. The consideration is that we want to match the size of public health expenditure as closely as possible for each country, then we see how well the model can match the mixture of public and private health expenditure given that the fitting exercise gives the model its best shot in matching the two moments.

That is, for each country, we iterate on values of $\rho \in[0,1)$ and $\phi_{H} \in(0,1)$ to minimize a weighted sum of the distance between the computed value of $\tau_{m}$ and its corresponding data value (with a weight of 100) and the distance between the computed value of $H_{m} /\left(H_{m}+\bar{h}\right)$ and its data counterpart (with a weight of 1 ). In each iteration, $\tau_{m}$ is computed from (25),

\footnotetext{
${ }^{16}$ We have also conducted a quantitative exercise to examine the role of income distribution in accounting for the observed differences in the mixture of health expenditure, which has been studied in some empirical studies, such as Di Matteo (2000). We assume that countries only differ in $\bar{y}$ and $y_{m} / \bar{y}$ and all other parameters take the baseline values as for Canada, then compute the model implied shares of public in total health expenditure. However, the computed shares of public health expenditure neither exhibit much variation across eountries nor are close to their data counterparts. Hence, income distribution does not seem to play an important role.

${ }^{17}$ Polity $I V$ dataset provides an index of democracy for all countries. This index is between 0 and 10 . Our sample includes OECD countries with the highest index of democracy (9 and 10). However, not all countries with the index of 9 and 10 are included in our sample due to data limitations. Figure 2 shows all countries in our sample.

${ }^{18}$ We can find data values for the moment $\bar{c} / \bar{y}$, however, matching this moment is equivalent to matching the mixture of health expenditure due to a linear relationship among consumption, private health expenditure and income given by (3).
} 
$H_{m}$ is the product of the computed $\tau_{m}$ and the country-specific $\bar{y}$ and $\bar{h}$ is again obtained from a numerical integration procedure as described in the baseline calibration using the country-specific log-normal income distribution.

TABLE 3

Inferred values for parameters and computed values for moments

\begin{tabular}{|l|c|c|c|c|c|c|}
\hline Country & $\rho$ & $\phi_{H}$ & $\frac{H_{m}}{H_{m}+h}$ & $\left.\frac{\text { Model }}{\text { Data }}\right|_{\frac{H_{m}}{H_{m}+h}}$ & $\tau_{m}$ & $\left.\frac{\text { Model }}{\text { Data }}\right|_{\tau_{m}}$ \\
\hline Australia & 0.0000 & 0.6075 & 0.6075 & 0.9104 & 0.0557 & 1.0012 \\
\hline Austria & 0.9097 & 0.5132 & 0.7614 & 1.0000 & 0.0782 & 1.0000 \\
\hline Canada & 0.6029 & 0.5839 & 0.7014 & 1.0000 & 0.0683 & 1.0000 \\
\hline Czech Republic & 0.0000 & 0.6739 & 0.6739 & 0.7665 & 0.0618 & 1.0036 \\
\hline Denmark & 0.0016 & 0.8327 & 0.8331 & 0.9977 & 0.0764 & 1.0000 \\
\hline Finland & 0.0000 & 0.6398 & 0.6398 & 0.8758 & 0.0587 & 1.0017 \\
\hline France & 0.9613 & 0.4929 & 0.7900 & 1.0000 & 0.0851 & 1.0000 \\
\hline Germany & 0.9427 & 0.5014 & 0.7793 & 1.0000 & 0.0821 & 1.0000 \\
\hline Greece & 0.0000 & 0.5892 & 0.5892 & 0.9817 & 0.0540 & 1.0002 \\
\hline Hungary & 0.0000 & 0.6001 & 0.6001 & 0.8420 & 0.0550 & 1.0022 \\
\hline Ireland & 0.0000 & 0.6162 & 0.6162 & 0.8064 & 0.0565 & 1.0029 \\
\hline Italy & 0.0000 & 0.7149 & 0.7149 & 0.9460 & 0.0655 & 1.0007 \\
\hline Japan & 0.0001 & 0.7143 & 0.7144 & 0.8744 & 0.0655 & 1.0018 \\
\hline Netherlands & 0.0000 & 0.5715 & 0.5715 & 0.9101 & 0.0524 & 1.0012 \\
\hline New Zealand & 0.0000 & 0.7302 & 0.7302 & 0.9358 & 0.0669 & 1.0008 \\
\hline Norway & 0.0000 & 0.8303 & 0.8303 & 0.9930 & 0.0761 & 1.0001 \\
\hline Portugal & 0.2615 & 0.6740 & 0.7211 & 1.0000 & 0.0684 & 1.0000 \\
\hline Spain & 0.0000 & 0.6252 & 0.6252 & 0.8773 & 0.0573 & 1.0017 \\
\hline Sweden & 0.0000 & 0.8145 & 0.8145 & 0.9908 & 0.0747 & 1.0001 \\
\hline Switzerland & 0.9680 & 0.4830 & 0.6393 & 1.0963 & 0.0631 & 0.9992 \\
\hline U.K. & 0.0000 & 0.7042 & 0.7042 & 0.8694 & 0.0646 & 1.0018 \\
\hline U.S. & 0.9756 & 0.4571 & 0.6276 & 1.4071 & 0.0670 & 0.9980 \\
\hline
\end{tabular}

Table 3 reports for each country the inferred values of $\rho$ and $\phi_{H}$, the $H_{m} /\left(H_{m}+\bar{h}\right)$ and $\tau_{m}$ values computed from the model and the matching of the two moments measured by the ratios of the computed values to their corresponding data values. Note that for all countries the ratios of the computed $\tau_{m}$ 's to their data counterparts deviate from 1 by less than 1\%, suggesting that the size of public health expenditure is exactly matched for each country at inferred values of $\rho$ and $\phi_{H}$ for that country.

Figure 2 illustrates the matching of the mixture of public and private health expenditure, by plotting the computed values of $H_{m} /\left(H_{m}+\bar{h}\right)$ against the corresponding data values for the 22 countries in the sample. As shown in Table 3 and Figure 2, the shares of public health expenditure are well matched for the majority of countries. The model achieves a perfect match for 7 countries: Austria, Denmark, France, Germany, Norway, Portugal and Sweden (Canada is excluded as it is the benchmark country for calibration), with the ratios of computed shares to the corresponding data values all between 0.99 and 1 . There is also a close match for Australia, Greece, Italy, Netherlands, New Zealand and Switzerland, with the 


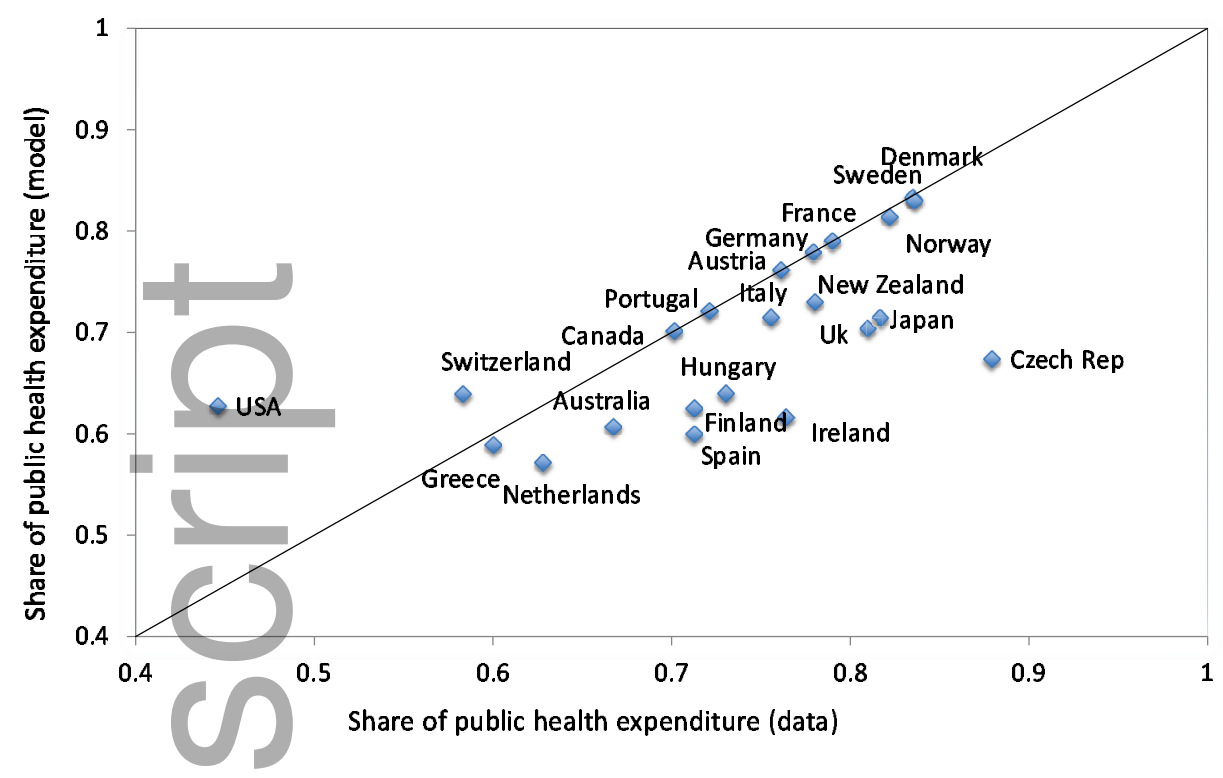

FIGURE 2 Shares of public health expenditure (model versus data)

ratios between 0.9 and 1.1. The model also matches quite well for other countries except the U.S. and Czech Republic. The overall correlation between the computed and actual shares of public health expenditure is 0.65. If we exclude the U.S. and Czech Republic, the correlation becomes 0.79 . These results suggest that the observed differences in the public-private mix of health expenditure across countries can be fairly well accounted for by variations in $\rho$ and $\phi_{H}$ across countries.

We consider the U.S. and Czech Republic to be outliers in the quantitative analysis. Among the countries in our sample, the U.S. has the highest total health expenditure relative to GDP (15\% of GDP on average in 2000s) and the lowest share of public in total health expenditure (45\%). In the model, public health is treated as a publicly financed universal health care system and the U.S. is the only country in the sample that does not have a universal public health care system. ${ }^{19}$ For Czech Republic, health care is highly centralized and there is only little role for the private sector in providing health care.

We now have a closer look at the inferred values of $\rho$ and $\phi_{H}$ for each country. According to Table 3 , the inferred values of $\phi_{H}$ demonstrate significant variations across countries. They are higher than 0.5 for all countries in the sample, except the U.S., Switzerland and France. In particular, Denmark, Italy, Japan, New Zealand, Norway, Sweden and the U.K. have $\phi_{H}$ values higher than 0.7 , suggesting that in these countries public health spending plays a more effective role in improving the health status of the society. The U.S. has the lowest $\phi_{H}$, with a value of 0.4571 .

The inferred values of $\rho$ vary substantially across countries, ranging from 0 to 0.9756 , implying that the elasticities of substitution between private and public health expenditure, $\varepsilon$, vary between 1 and 41.05 for countries in the sample. The values of $\rho$ are essentially zero for many countries: Australia, Czech Republic, Denmark, Finland, Greece, Hungary,

${ }^{19}$ The two main public health programs in the U.S., Medicare and Medicaid, only provide coverage to particular groups of people: Medicare is for people who are above 65 years of age or permanently disabled and Medicaid is for low-income families. 
Ireland, Italy, Japan, the Netherlands, New Zealand, Norway, Spain, Sweden and the U.K.. When $\rho$ is 0 or $\varepsilon$ is 1 , public and private health spending are complementary in improving the health status of a society and the health technology defined in (2) reduces to a CobbDouglas form. This result suggests that for these countries a Cobb-Douglas form can be a good approximation for the health technology. On the contrary, the values of $\rho$ are not far from 1 for several other countries: Austria, France, Germany, Switzerland and the U.S., suggesting that for these countries public and private health spending are close to be perfectly substitutable and a linear form can be a good approximation for the health technology.

Recall that $\rho$ and $\phi_{H}$ indicate the degree of substitutability between public and private health spending and their relative effectiveness in improving health outcome. They summarize in reduced form a complex interaction of public and private health care in a society under the particular health care system. Our quantitative exercise provides a way to infer the values of these two factors for each country. In particular, our results imply that public and private health spending are complementary in the U.K. and substitutable in the U.S.. This is consistent with existing empirical findings. For example, Propper (2000) examines the choice between public and private health care using the British Household Panel Survey between 1991 and 2000 and finds that private health appears to be complementary to public health. Cutler and Gruber (1996, 1996b) and Gruber and Simon (2008) study the impact on private health insurance of an increase in the coverage of Medicaid and Medicare in the U.S. and find that the increase in public health coverage has crowded out private health insurance substantially, suggesting that public and private health are highly substitutable. ${ }^{20}$

Knowing about the interaction of public and private health care is important for the design or reform of health care policies that aim to achieve efficiency and equity in health care. To illustrate this, we now use our estimates for $\rho$ and $\phi_{H}$, as a reduced form representation of the public-private interaction, to run two experiments that show how important these primitives are for health outcomes. In the first experiment, we consider a reduction in public health expenditure and show that different public-private interactions in health care systems, as indicated by different $\rho$ and $\phi_{H}$ values, can lead to very different outcomes. In the second experiment, we show that a large fraction of differences in health inequality across countries can be accounted for by differences in the way public and private health care interact.

\subsection{Experiments}

In the two experiments below, we take Denmark and Austria as examples. There are several reasons for this choice. First, Denmark and Austria are among the several countries for which the estimates of $\rho$ and $\phi_{H}$ achieve a perfect match in the quantitative exercise. Second, the estimates of $\rho$ and $\phi_{H}$ for Denmark (0.0016 and 0.8327) and Austria (0.9097 and 0.5132) represent two very different health systems, with public health spending being more effective and much less substitutable with private health spending in Denmark than in Austria. Third, these two countries have very similar ratios of public health expenditure to GDP or majority choices of tax rate $\left(\tau_{m}\right)$. The figures for the experiments are based on 20, 000 random income draws and are given in Appendix C.

${ }^{20}$ Discussions on the health care systems in OJRBK (2012) and Chernichovsky (2000) indicate that public and private health spending are complementary in Denmark and Australia. This is in line with our findings.

This article is protected by copyright. A円1 rights reserved 
Experiment One

The first experiment is motivated by a health care reform that has often been considered in advanced economies-budget caps in public financing of health care, in light of budgetary challenges (due to aging population, public debt overhang, slow economic growth, etc.). We examine the health outcomes of a $10 \%$ reduction in the public health expenditure for Denmark, i.e., $\tau_{m}$ reduces from 0.0764 to $0.0688 .{ }^{21}$ To highlight the importance of public-private health interactions for policy outcomes, we also consider the same policy for a hypothetical economy which is the same as Denmark on every dimension except that its health system is a very different one that is characterized by Austria's $\rho$ and $\phi_{H}$.

As shown in Table 4 and Figure C1, for Denmark, the 10\% reduction in public health spending leads to negligible changes in individuals' private health spending, leaving average private health spending almost unchanged. As a result, total health spending as a ratio of GDP falls by $8.19 \%$ and the share of public health spending falls only by $1.97 \%$. For health status, the reduction in public health spending shifts its distribution to the left, with no change in health inequality (as measured by the median to mean ratio, $X_{m} / \bar{X}$ ) but a significant fall of $8.28 \%$ in its average level. However, for the hypothetical economy, with public health spending being less effective than in Denmark and highly substitutable with private health spending, the cut in public health spending leads to significant increases in individuals' private health spending, causing average private health spending to rise and inequality in private health spending to fall substantially. Consequently, total health spending ratio only falls by $3.04 \%$ while the share of public health spending falls by $7.18 \%$. Because of the large rise in private health spending, average health status only falls by $2.75 \%$ and health inequality slightly improves.

TABLE 4

Results of Experiment One

\begin{tabular}{|c|c|c|c|c|c|}
\hline $\bar{h}$ & $\frac{h_{m}}{h}$ & $\overline{\bar{X}}$ & $\frac{X_{m}}{\bar{X}}$ & $\frac{H_{m}}{H_{m}+h}$ & $\frac{\overline{H_{m}+h}}{\bar{y}}$ \\
\hline \multicolumn{6}{|c|}{ Denmark with its own $\rho$ and $\phi_{H}$} \\
\hline $\begin{array}{c}\tau_{m}=0.0764 \quad 501.0 \\
\end{array}$ & 0.943 & 1896.3 & 0.998 & 0.833 & 0.092 \\
\hline$\tau_{m}=0.0688 \quad 505.3$ & 0.943 & 1739.3 & 0.998 & 0.817 & 0.084 \\
\hline$\%$ change & 0 & -8.28 & 0 & -1.97 & -8.19 \\
\hline \multicolumn{6}{|c|}{ Denmark with Austria's $\rho$ and $\phi_{H}$} \\
\hline $\begin{array}{ll}\tau_{m}=0.0764 & 746.1\end{array}$ & 0.714 & 1611.8 & 0.938 & 0.770 & 0.099 \\
\hline$\tau_{m}=0.0688 \quad 897.7$ & 0.777 & 1567.5 & 0.941 & 0.715 & 0.096 \\
\hline 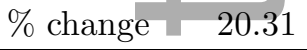 & 8.91 & -2.75 & 0.38 & -7.18 & -3.04 \\
\hline
\end{tabular}

In short, these results imply that a cut in public health spending is less costly when public and private health spending are more substitutable, as it leads to a much smaller reduction in average health status and some improvement in health inequality. This experiment suggests that the same health care policy can lead to very different health outcomes, depending on the particular interaction of public and private sectors within a health care system, as represented by $\rho$ and $\phi_{H}$.

${ }^{21}$ According to Cottarelli (2010), Denmark is among the 11 OECD countries that has the fastest growth in public health spending since 2000 and this IMF report recommends a budget cap as a potential reform strategy for Denmark to reduce the growth of public health spending.

This article is protected by copyright. A円2rights reserved 
Experiment Two

In the second experiment, we use our estimates to examine the role of public-private health interaction in accounting for differences in health inequality. Improving the overall health status and health inequality has always been an important goal of a society and this issue has also been extensively studied in the health literature. Most empirical studies on health inequality focus on the roles of income distribution and other socioeconomic factors (e.g., see Doorslaer and Koolman 2004; Lynch, Smith, Harper, Hillemeier, Ross, Kaplan and Wolfson 2004). However, the interaction between public and private health care has largely been ignored. Using our estimates for $\rho$ and $\phi_{H}$, we illustrate in this experiment the importance of such interaction relative to income distribution in determining health inequality.

We consider Denmark, Austria and a hypothetical economy which is the same as Denmark except that its health system is characterized by Austria's $\rho$ and $\phi_{H} \cdot{ }^{22}$ That is, Denmark and the hypothetical economy differ only by public-private health interactions, while the hypothetical economy and Austria differ only by income distributions (we use Denmark's $\tau_{m}$ for all three economies). A comparison of the health outcomes in the three economies then tells us the relative contributions of income distribution and public-private interaction.

As shown in Table 5 and Figure C2, the degree of health inequality $\left(X_{m} / \bar{X}\right)$ is higher in Austria than in Denmark. The dispersion in the distribution of health status (as measured by the coefficient of variation, $X_{c v}$ ) is also much higher in Austria than in Denmark. These differences are caused by differences in both income distributions and health systems between Denmark and Austria: income inequality is higher and public and private health spending are more substitutable in Austria than in Denmark. When public and private health are more substitutable, high income individuals spend more on private health and low income individuals spend less on private health and so leading to higher inequality in health status. Higher income inequality could also lead to higher health inequality, given that the income elasticity of private health spending is greater than one in our model (see Proposition 1 (i)).

TABLE 5

Results of Experiment Two

\begin{tabular}{lcccccc}
\hline \hline & $h$ & $\frac{h_{m}}{\bar{h}}$ & $h_{c v}$ & $\bar{X}$ & $\frac{X_{m}}{\bar{X}}$ & $X_{c v}$ \\
\hline Denmark & 501.0 & 0.943 & 0.353 & 1896.3 & 0.998 & 0.057 \\
Denmark with Austria's $\rho$ and $\phi_{H}$ & 746.1 & 0.714 & 1.003 & 1611.8 & 0.938 & 0.239 \\
Austria & 856.0 & 0.511 & 1.330 & 1694.1 & 0.882 & 0.339 \\
\hline \multicolumn{2}{c}{ Decomposing the total change from Denmark to Austria } \\
\hline $\begin{array}{l}\text { Income Distribution } \\
\text { In } \phi_{H}\end{array}$ & 69.06 & 53.15 & 66.49 & 140.69 & 52.09 & 64.39 \\
\hline \hline
\end{tabular}

We further decompose the differences in health outcomes between Denmark and Aus-

${ }^{22}$ Denmark and Austria have very similar marital and activity status such as marriage rate, unemployment rate and the ratio of part-time to total employment (computed from World Development Indicator and UN Marriage Database for 2000s). These factors are identified as important determinants for health inequality (Doorslaer and Koolman 2004). However, their income distirbutions are quite different, with $\bar{y}$ given by 32, 743.5 for Denmark and 33,639.2 for Austria and $y_{m} / \bar{y}$ given by 0.9431 for Denmark and 0.8898 for Austria.

This article is protected by copyright. Ał3rights reserved 
tria into contributions from public-private health interaction (by comparing the results for Denmark and the hypothetical economy) and from income distribution (by comparing the results for the hypothetical economy and Austria). The results in Table 5 suggest that both are important, with public-private health interaction playing a larger role than income distribution. In particular, changes in $\rho$ and $\phi_{H}$ account for $52.09 \%$ of the increase in health inequality in Austria compared to Denmark and $64.39 \%$ of the increase in the dispersion of health status.

This experiment suggests that the interaction between public and private sectors in a health care system plays a quantitatively important role in determining the health inequality in a society. Two countries that have similar size of public health expenditure relative to GDP, like Denmark and Austria, can have very different health inequality if they have different interactions between public and private health care. A country can improve its health inequality by changing the way these two interact. Again, our estimates of $\rho$ and $\phi_{H}$ can provide useful information for this discussion.

\section{Concluding Remarks}

Despite the large differences in the mixture of public and private health expenditure across countries, factors that critically affect the composition of health expenditure have rarely been examined analytically and empirically in existing literature. In this study, we examined, in the context of a simple voting model, how the public-private mix of health spending is determined through majority voting and how this decision is affected by various preference, economic and institutional factors. Further, we calibrated the model and conducted a quantitative exercise for a group of advanced democratic countries to explore what factors might account for the observed variations in the public-private mix of health expenditure.

The quantitative exercise revealed the importance of the substitutability between public and private health spending and their relative effectiveness in determining the public-private mix of health expenditure and in accounting for the cross-country differences. These two factors summarize in reduced form a complex interaction between public and private sectors within a health care system. The quantitative exercise provided a way to infer these two factors which are not easily observable. These estimates could be utilized in policy analysis or future empirical and quantitative research. As demonstrated in the two experiments, differences in these factors can lead to quantitatively significant differences in health outcomes.

As one of the first few attempts to formally examine the public-private mix of health expenditure, this study considered several important factors for decisions concerning public and private health spending, namely, preference, income and health technology. The model can be extended to incorporate several other factors that are potentially important for the mixture of health spending, such as the pricing of public and private health services and the age-dependent demand for health care services. An increase in the prices of private health care services would lead to a higher share of private health expenditure if the degree of substitutability between private and public health care is low. Also, health expenditure is typically highly concentrated; old people account for a much larger fraction of total health spending relative to their population share. In fact, most countries in our sample have an aging population, which implies a higher demand for health care services, especially for public long-term health care.

This article is protected by copyright. A円4rights reserved 
Incorporating prices of public and private health care in our static model does not change the analytical characterization of the model, however, the quantitative analysis would require data on the prices of public and private health care services across countries. Considering age-dependent demand for health care would require a more substantive extension to a dynamic setting than we had in Section 3.2. We need to consider the demand for health expenditure by both young and old people and allow both groups to vote in any given period.

In addition, the substantial differences across countries in our estimates for the substitutability between public and private health expenditure and their relative effectiveness call for a further investigation into deeper forces underlying these differences, whether they are health institutions or demographical and political factors. These are left for future research.

\section{References}

Ássa, R., and F. Pueyo (2006) "Government health spending and growth in a model of endogenous longevity." Economics Letters 90(2), 249-253

Battistin, E., R. Blundell and A. Lewbel (2009) "Why is consumption more log normal than income? Gibrat's law revisited." Journal of Political Economy 117(6), 1140-1154

Bethencourt, C., and V. Galasso (2008) "Political complements in the welfare state: Health care and social security." Journal of Public Economics 92(3), 609-632

Bhattacharya, J., and X. Qiao (2007) "Public and private expenditure on health in a growth model." Journal of Economic Dynamics and Control 31(8), 2519-2535

Blackburn, K, and G. P. Cipriani (2002) "A model of longevity, fertility and growth." Journal of Economic Dynamics and Control 26(2), 187-204

Brzozowski, M., M. Gervais, P. Klein and M. Suzuki (2010) "Consumption, income, and wealth inequality in Canada." Review of Economic Dynamics 13(1), 52-75

Chakraborty, S. (2004) "Endogenous lifetime and economic growth." Journal of Economic Theory 116(1), 119-137

Chakraborty, S., and M. Das (2005) "Mortality, human capital and persistent inequality." Journal of Economic Growth 10(2), 159-192

Chernichovsky, D. (2000) "The public-private mix in the modern health care system: concepts, issues, and policy options revisited." National Bureau of Economic Research, No. w7881

Cottarelli, C. (2010) "Macro-fiscal implications of health care reform in advanced and emerging economies." International Monetary Fund, 28

Cutler, D., A. Deaton and A. Lleras-Muney (2006) "The determinants of mortality." Journal of Economic Perspectives 20(3), 97-120

Cutler, D., and J. Gruber (1996) "The effects of Medicaid expansions on public insurance, private insurance, and redistribution," American Economic Review 86(2), 378-383

- (1996b) "Does public health insurance crowd out private insurance?" Quarterly Journal of Economics 111(2), 391-430

De Nardi, M., E. French and J.B. Jones (2010) "Why do the elderly save? The role of medical expenses." Journal of Political Economy 118(1), 39-75

Di Matteo, L. (2000) "The determinants of the public-private mix in Canadian health care expenditures: 1975-1996." Health Policy 52(2), 87-112

Doorslaer, E. V., and X. Koolman (2004) "Explaining the differences in income-related health inequalities across European countries." Health Economics 13(7), 609-628

\section{This article is protected by copyright. A45rights reserved}


Epple, D., and R.E. Romano (1996) "Public provision of private goods." Journal of Political Economy 104(1), 57-84

Feinstein, J.S. (1993) "The relationship between socioeconomic status and health: a review of the literature." The Milbank Quarterly 71, 279-322

Gerdtham, U.-G., J. Sogaard, F. Andersson and B. Jonsson (1992) "An econometric analysis of health care expenditure: a cross-section of OECD countries." Journal of Health Economics 11(1), 63-84

Gouveia, M. (1997) "Majority rule and the public provision of a private good." Public Choice 93(3-4), $221-244$

Gruber, J., and K. Simon (2008) "Crowd-out ten years later: have recent public insurance expansions crowded out private health insurance?" Journal of Health Economics 27(2), 201-217

Gupta, R., and C. Vermeulen (2010) "Private and public health expenditures in an endogenous growth model with inflation targeting." Annals of Economics and Finance 11(1), 139-153

Hall, R.E., and C.I. Jones (2007) "The value of life and the rise in health spending." The Quarterly Journal of Economics 122(1), 39-72

Harrison, A.J., (1981) "Earnings by size: a tale of two distributions." Review of Economic Studies 48(4), 621-631

Hitiris, T., and J. Posnett (1992) "The determinants and effects of health expenditure in developed countries." Journal of Health Economics 11(2), 173-181

Hsu, M., and J. Lee (2013) "The provision of public universal health insurance: impacts on private insurance, asset holdings, and welfare." Macroeconomic Dynamics 17(6), 1252-1280

Jung, J., C. Tran (2010) "Medical consumption over the life cycle: facts from a U.S. medical expenditure panel survey." Towson University Department of Economics Working Paper Series, No. 2010-09

Kifmann, M. (2005) "Health insurance in a democracy: why is it public and why are premiums incomerelated?" Public Choice 124(3-4), 283-308

Krusell, P., and J.V. Rios-Rull (1999) "On the size of U.S. government: political economy in the neoclassical growth model." American Economic Review, 89(5), 1156-81

Lahiri, R., and E. Richardson (2008) "Public and private expenditures on health in the presence of inequality and endogenous mortality: a political economy perspective." School of Economics and Finance University of Queensland, Working Papers Series 240

Lynch, J., G.D. Smith, S. Harper, M. Hillemeier, N. Ross, G.A. Kaplan and M. Wolfson (2004) "Is income inequality a determinant of population health? Part 1. A systematic review." Milbank Quarterly 82(1), 5-99

Meltzer, A.H., and S.F. Richard (1981) "A rational theory of the size of government." Journal of Political Economy 89(5), 914-27

Newhouse, J.P. (1977) "Medical-care expenditure: a cross-national survey." Journal of Human Resources $12(1), 115-125$

Nishino, H., and K. Kakamu (2011) "Grouped data estimation and testing of Gini coefficients using lognormal distributions." The Indian Journal of Statistics 73(2), 193-210

Olejaz, M., A. Juul, A. Rudkjøbing, H. O. Birk and A. Krasnik (2012) "Denmark health system review: health systems in transition." World Health Organization

Parker, S.W, and R. Wong (1997) "Household income and health care expenditures in Mexico." Health Policy 40(3), 237-255

Philipson, T.J., and G.S. Becker (1998) "Old-age longevity and mortality-contingent claims." Journal of Political Economy 106(3), 551-573

Pritchett, L., and L.H. Summers (1996) "Wealthier is healthier." Journal of Human Resources 31(4), 841-868

\section{This article is protected by copyright. Af6rights reserved}


Propper, C. (2000) "The demand for private health care in the U.K." Journal of Health Economics $19(6), 855-876$

Scanlon, W.J. (1980) "A theory of the nursing home market." Inquiry, 17, 25-41

Tang, K.K., and J. Zhang (2007) "Health, education, and life cycle savings in the development process." Economic Inquiry 45(3), 615-630

Zhang, J., J. Zhang and M. Leung (2006) "Health investment, saving, and public policy." Canadian Journal of Economics 39(1), 68-93

-
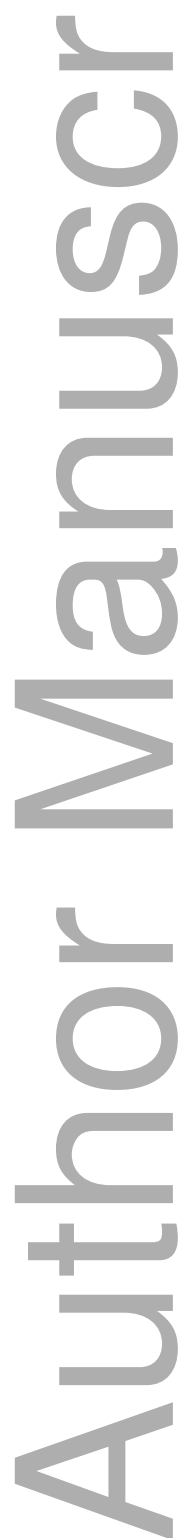


\section{Appendix A. Proofs of Proposition 1 and 2}

Proof of Proposition 1. (i) Rewrite (6) as

$$
\Upsilon_{i} \equiv\left(\phi_{H} H^{\rho}+\phi_{h} h_{i}^{\rho}\right) h_{i}^{1-\rho}-\gamma \phi_{h}\left[(1-\tau) y_{i}-h_{i}\right]=0,
$$

which implicitly determines the optimal private health spending of agent $i, h\left(y_{i} ; \tau\right)$, given $H=\tau \bar{y}$. By implicit function theorem, we obtain

$$
\frac{\partial h}{\partial y_{i}}=-\frac{\frac{\partial \Upsilon_{i}}{\partial y_{i}}}{\frac{\partial \Upsilon_{i}}{\partial h_{i}}},
$$

where $\partial \Upsilon_{i} / \partial y_{i}$ and $\partial \Upsilon_{i} / \partial h_{i}$ are partial derivatives of $\Upsilon_{i}$ with respect to $y_{i}$ and $h_{i}$ evaluated at the optimal $h_{i}$ given by $h\left(y_{i} ; \tau\right)$. Since

$$
\begin{gathered}
\frac{\partial \Upsilon_{i}}{\partial y_{i}}=-(1-\tau) \gamma \phi_{h}<0, \\
\frac{\partial \Upsilon_{i}}{\partial h_{i}}=\left(\phi_{H} H^{\rho}+\phi_{h}\left(h\left(y_{i} ; \tau\right)\right)^{\rho}\right)(1-\rho)\left(h\left(y_{i} ; \tau\right)\right)^{-\rho}+\phi_{h}(\rho+\gamma)>0,
\end{gathered}
$$

we have $\partial h / \partial y_{i}>0$. Using (A1) and (A2), the income elasticity of private health spending $\frac{\partial h}{\partial y_{i}} \frac{y_{i}}{h\left(y_{i} ; \tau\right)}=\frac{\left(\phi_{H} H^{\rho}+\phi_{h}\left(h\left(y_{i} ; \tau\right)\right)^{\rho}\right)\left(h\left(y_{i} ; \tau\right)\right)^{1-\rho}+\phi_{h} \gamma h\left(y_{i} ; \tau\right)}{\left(\phi_{H} H^{\rho}+\phi_{h}\left(h\left(y_{i} ; \tau\right)\right)^{\rho}\right)\left(h\left(y_{i} ; \tau\right)\right)^{1-\rho}+\phi_{h} \gamma h\left(y_{i} ; \tau\right)-\rho \phi_{H} H^{\rho}\left(h\left(y_{i} ; \tau\right)\right)^{1-\rho}}>1$

(ii) Using (A1), we obtain

$$
\frac{\partial h}{\partial \tau}=-\frac{\frac{\partial \Upsilon_{i}}{\partial \tau}}{\frac{\partial \Upsilon_{i}}{\partial h_{i}}}, \quad \text { where } \frac{\partial \Upsilon_{i}}{\partial \tau}=\left(h\left(y_{i} ; \tau\right)\right)^{1-\rho} \phi_{H} \rho H^{\rho-1} \bar{y}+y_{i} \gamma \phi_{h}>0 .
$$

Thus, $\partial h / \partial \tau<0$, given that $\partial \Upsilon_{i} / \partial h_{i}>0$ from (A3).

(iii) Using (A1), we obtain

$$
\frac{\partial h}{\partial \bar{y}}=-\frac{\frac{\partial \Upsilon_{i}}{\partial \bar{y}}}{\frac{\partial \Upsilon_{i}}{\partial h_{i}}}<0, \quad \text { where } \frac{\partial \Upsilon_{i}}{\partial \bar{y}}=\left(h\left(y_{i} ; \tau\right)\right)^{1-\rho} \phi_{H} \rho H^{\rho-1} \tau>0
$$

(iv) Using (A1), we obtain

$$
\frac{\partial h}{\partial \phi_{H}}=-\frac{\frac{\partial \Upsilon_{i}}{\partial \phi_{H}}}{\frac{\partial \Upsilon_{i}}{\partial h_{i}}}<0, \quad \text { where } \frac{\partial \Upsilon_{i}}{\partial \phi_{H}}=\frac{\left(h\left(y_{i} ; \tau\right)\right)^{1-\rho} H^{\rho}}{\phi_{h}}>0
$$

(v) Using (A1), we obtain

$$
\frac{\partial h}{\partial \gamma}=-\frac{\frac{\partial \Upsilon_{i}}{\partial \gamma}}{\frac{\partial \Upsilon_{i}}{\partial h_{i}}}>0, \quad \text { where } \frac{\partial \Upsilon_{i}}{\partial \gamma}=\phi_{h}\left[h\left(y_{i} ; \tau\right)-(1-\tau) y_{i}\right]<0 .
$$


(vi) Using (A1), we obtain

$$
\frac{\partial h}{\partial \rho}=-\frac{\frac{\partial \Upsilon_{i}}{\partial \rho}}{\frac{\partial \Upsilon_{i}}{\partial h_{i}}}, \quad \text { where } \frac{\partial \Upsilon_{i}}{\partial \rho}=\phi_{H} H^{\rho}\left(h\left(y_{i} ; \tau\right)\right)^{1-\rho} \ln \left(H / h\left(y_{i} ; \tau\right)\right) .
$$

Thus, $\partial h / \partial \rho<(=,>) 0$ if $h\left(y_{i} ; \tau\right) / H<(=,>) 1$.

(vii) Let $y_{i}$ and $\bar{y}$ both change by a factor $\alpha \neq 1$, where $\alpha$ is a positive constant. Suppose the optimal private health spending, as implicitly determined by (A.1), changes by a factor $\alpha^{k}$, where $k$ is a positive constant. We want to show that $k=1$. Then (A.1) becomes

$$
\left[\phi_{H}(\alpha H)^{\rho}+\phi_{h}\left(\alpha^{k} h_{i}\right)^{\rho}\right]\left(\alpha^{k} h_{i}\right)^{1-\rho}-\gamma \phi_{h}\left[(1-\tau) \alpha y_{i}-\alpha^{k} h_{i}\right]=0
$$

Simplifying the equation above yields

$$
\int \phi_{H} H^{\rho} h_{i}^{1-\rho} \alpha^{\rho+k(1-\rho)}+(1+\gamma) \phi_{h} h_{i} \alpha^{k}-\gamma \phi_{h}(1-\tau) y_{i} \alpha=0
$$

From (A.1), we have $\phi_{H} H^{\rho} h_{i}^{1-\rho}=\gamma \phi_{h}(1-\tau) y_{i}-(1+\gamma) \phi_{h} h_{i}$. Plugging this expression into the equation above, we obtain

$$
\left[\gamma \phi_{h}(1-\tau) y_{i}\left(\alpha^{\rho+k(1-\rho)}-\alpha\right)\right]+\left[(1+\gamma) \phi_{h} h_{i} \alpha^{k}\left(1-\alpha^{(1-k) \rho}\right)\right]=0 .
$$

If $k>1$, the two terms in the two brackets are both positive if $\alpha>1$ and both negative if $\alpha<1$, so the equation above cannot hold no matter $\alpha$ greater or less than one. Similarly, we can show that the equation above cannot hold if $k<1$. So we must have $k=1$.

QED

Proof of Proposition 2. By (8), the sign of $\partial V_{i} / \partial \tau$ is determined by the sign of the term given in the bracket which is $-\phi_{h} y_{i}+\phi_{H} \bar{y}\left[h\left(y_{i} ; \tau\right) /(\tau \bar{y})\right]^{1-\rho} \equiv \Xi_{i}$, where $\rho \in[0,1)$. For $\tau \in[0,1), h\left(y_{i} ; \tau\right)$ is strictly positive and decreases in $\tau$ by Proposition $1(\mathrm{ii})$, so $\Xi_{i}$ decreases in $\tau$. When $\tau \rightarrow 0, \Xi_{i} \rightarrow+\infty$, so $\partial V_{i} / \partial \tau \rightarrow+\infty$. When $\tau \rightarrow 1, h\left(y_{i} ; \tau\right) \rightarrow 0$, so $\Xi_{i}<0$ and hence $\partial V_{i} / \partial \tau<0$. Thus, the sign of $\partial V_{i} / \partial \tau$ changes from positive to negative when $\tau$ rises from zero to one. This means $V_{i}$ is strictly quasi-concave in $\tau$ and thus voters' preferences are single-peaked such that a unique voting equilibrium exists. From (10), it is obvious that the preferred tax rates of voters are monotonically decreasing in their incomes such that the equilibrium tax rate is the preferred tax rate of the voter with median income.

QED

\section{Appendix B. Working with General Functions}

Comparative statics of the optimal private health spending

The optimal private health spending $h\left(y_{i} ; \tau\right)$ is determined by $(13)$. Define

$$
\Phi_{i} \equiv-\partial u / \partial c_{i}+\left(\partial u / \partial X_{i}\right)\left(\partial X / \partial h_{i}\right)=0,
$$

then using implicit function theorem, we have 


$$
\begin{aligned}
& \frac{\partial h}{\partial y_{i}}=-\frac{\frac{\partial \Phi_{i}}{\partial y_{i}}}{\frac{\partial \Phi_{i}}{\partial h_{i}}}=-\frac{-\frac{\partial^{2} u}{\partial c_{i}^{2}}(1-\tau)}{\frac{\partial^{2} u}{\partial c_{i}^{2}}+\frac{\partial^{2} u}{\partial X_{i}^{2}}\left(\frac{\partial X}{\partial h_{i}}\right)^{2}+\frac{\partial u}{\partial X_{i}} \frac{\partial^{2} X}{\partial h_{i}^{2}}} \\
& \frac{\partial h}{\partial \tau}=-\frac{\frac{\partial \Phi_{i}}{\partial \tau}}{\frac{\partial \Phi_{i}}{\partial h_{i}}}=-\frac{y_{i} \frac{\partial^{2} u}{\partial c_{i}^{2}}+\left(\frac{\partial^{2} u}{\partial X_{i}^{2}} \frac{\partial X}{\partial h_{i}} \frac{\partial X}{\partial H}+\frac{\partial u}{\partial X_{i}} \frac{\partial^{2} X}{\partial h_{i} \partial H}\right) \bar{y}}{\frac{\partial^{2} u}{\partial c_{i}^{2}}+\frac{\partial^{2} u}{\partial X_{i}^{2}}\left(\frac{\partial X}{\partial h_{i}}\right)^{2}+\frac{\partial u}{\partial X_{i}} \frac{\partial^{2} X}{\partial h_{i}^{2}}} \\
& \frac{\partial h}{\partial \bar{y}}=-\frac{\frac{\partial \Phi_{i}}{\partial \bar{y}}}{\frac{\partial \Phi_{i}}{\partial h_{i}}}=-\frac{\left(\frac{\partial^{2} u}{\partial X_{i}^{2}} \frac{\partial X}{\partial h_{i}} \frac{\partial X}{\partial H}+\frac{\partial u}{\partial X_{i}} \frac{\partial^{2} X}{\partial h_{i} \partial H}\right) \tau}{\frac{\partial^{2} u}{\partial c_{i}^{2}}+\frac{\partial^{2} u}{\partial X_{i}^{2}}\left(\frac{\partial X}{\partial h_{i}}\right)^{2}+\frac{\partial u}{\partial X_{i}} \frac{\partial^{2} X}{\partial h_{i}^{2}}}
\end{aligned}
$$

Since $\partial \Phi_{i} / \partial h_{i}<0, \partial h / \partial y_{i}>0$. If $\left(\partial^{2} u / \partial X_{i}^{2}\right)\left(\partial X / \partial h_{i}\right)(\partial X / \partial H)+\left(\partial u / \partial X_{i}\right)\left(\partial^{2} X / \partial h_{i} \partial H\right)<$ 0 , then we also have $\partial h / \partial \tau<0$ and $\partial h / \partial \bar{y}<0$. A sufficient condition for this inequality to hold is that $u$ is sufficiently concave (such that $\partial^{2} u / \partial X_{i}^{2}$ has a large negative value) and the elasticity of substitution between $h$ and $H$ in the health production function $X$ is sufficiently large (such that $\partial^{2} X / \partial h_{i} \partial H$ has a small positive value).

Existence and uniqueness of the voting equilibrium

The indirect utility $V_{i}$, as given in (14), is strictly quasi-concave in $\tau$. This is because: when $\tau \rightarrow 0$, we have $H \rightarrow 0$ and $\partial X / \partial H \rightarrow+\infty$, hence $\partial V_{i} / \partial \tau \rightarrow+\infty$; and when $\tau \rightarrow 1$, we have $h_{i} \rightarrow 0$ and $\partial X / \partial h_{i} \rightarrow+\infty$, hence $\partial V_{i} / \partial \tau \rightarrow-\infty$. Therefore, voters' preferences are single-peaked in $\tau$ such that a unique majority voting equilibrium exists.

Next, we show that agents' preferred tax rates are monotonically decreasing with their incomes, i.e., $\partial \tau_{i} / \partial y_{i}<0$. Using (14), define $\Omega_{i} \equiv-\left(\partial X / \partial h_{i}\right) y_{i}+(\partial X / \partial H) \bar{y}=0$, then

$$
\frac{\partial \tau_{i}}{\partial y_{i}}=-\frac{\frac{\partial \Omega_{i}}{\partial y_{i}}}{\frac{\partial \Omega_{i}}{\partial \tau_{i}}}=-\frac{-\frac{\partial X}{\partial h_{i}}+\left(\bar{y} \frac{\partial^{2} X}{\partial h_{i} \partial H}-y_{i} \frac{\partial^{2} X}{\partial h_{i}^{2}}\right) \frac{\partial h}{\partial y_{i}}}{-y_{i}\left(\frac{\partial^{2} X}{\partial h_{i}^{2}} \frac{\partial h}{\partial \tau_{i}}+\frac{\partial^{2} X}{\partial h_{i} \partial H} \bar{y}\right)+\bar{y}\left(\frac{\partial^{2} X}{\partial h_{i} \partial H} \frac{\partial h}{\partial \tau_{i}}+\frac{\partial^{2} X}{\partial H^{2}} \bar{y}\right)}
$$

Since $\partial \Omega_{i} / \partial \tau_{i}<0$, if $\partial \Omega_{i} / \partial y_{i}<0$, then $\partial \tau_{i} / \partial y_{i}<0$. For $\partial \Omega_{i} / \partial y_{i}<0$ to hold, we need $\partial^{2} X / \partial h_{i} \partial H$ and $-\partial^{2} X / \partial h_{i}^{2}$ to be sufficiently small, which tend to hold if the elasticity of substitution between $h$ and $H$ in the health production function $X$ is sufficiently large and $X$ is sufficiently less concave. Thus, under this sufficient condition, $\partial \tau_{i} / \partial y_{i}<0$, and the majority choice of the tax rate is simply the preferred tax rate of the voter with median income.

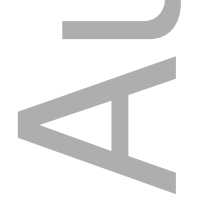




\section{Appendix C. Figures for Experiment One and Two}
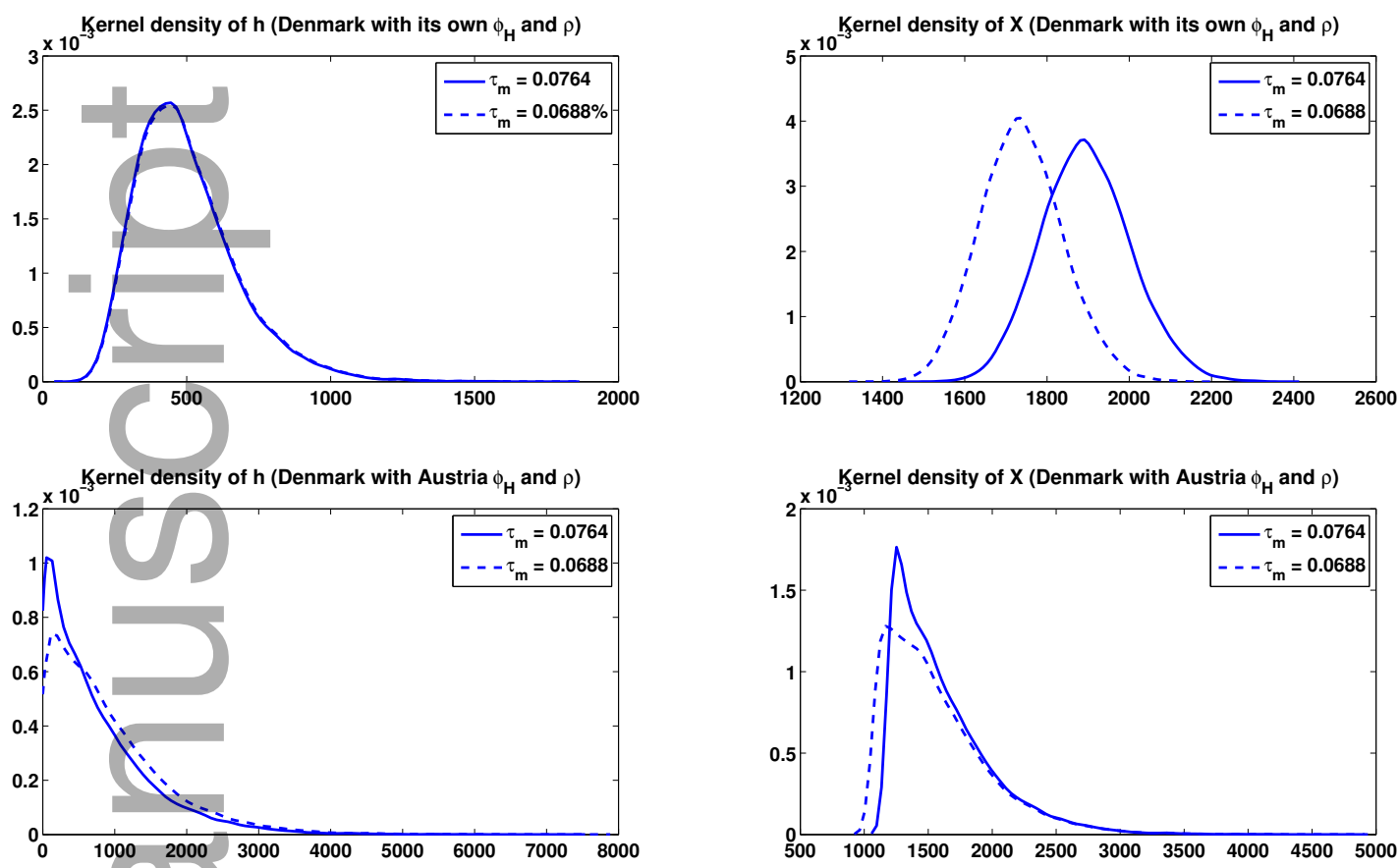

FiguRE C1 Distributions of private health spending and health status in Experiment One
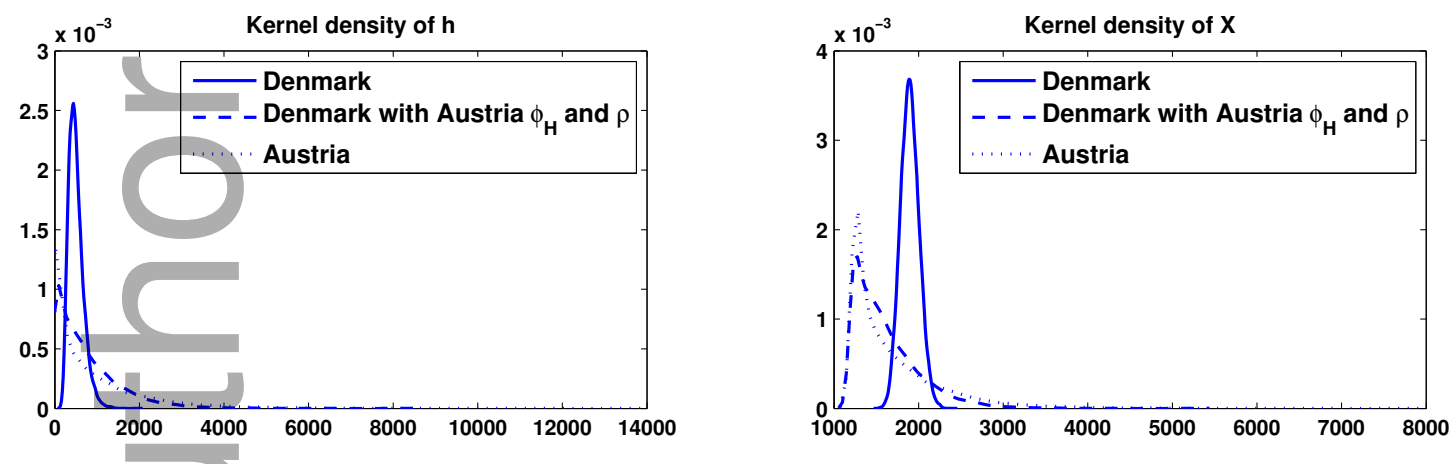

Figure C2 Distributions of private health spending and health status in Experiment Two 

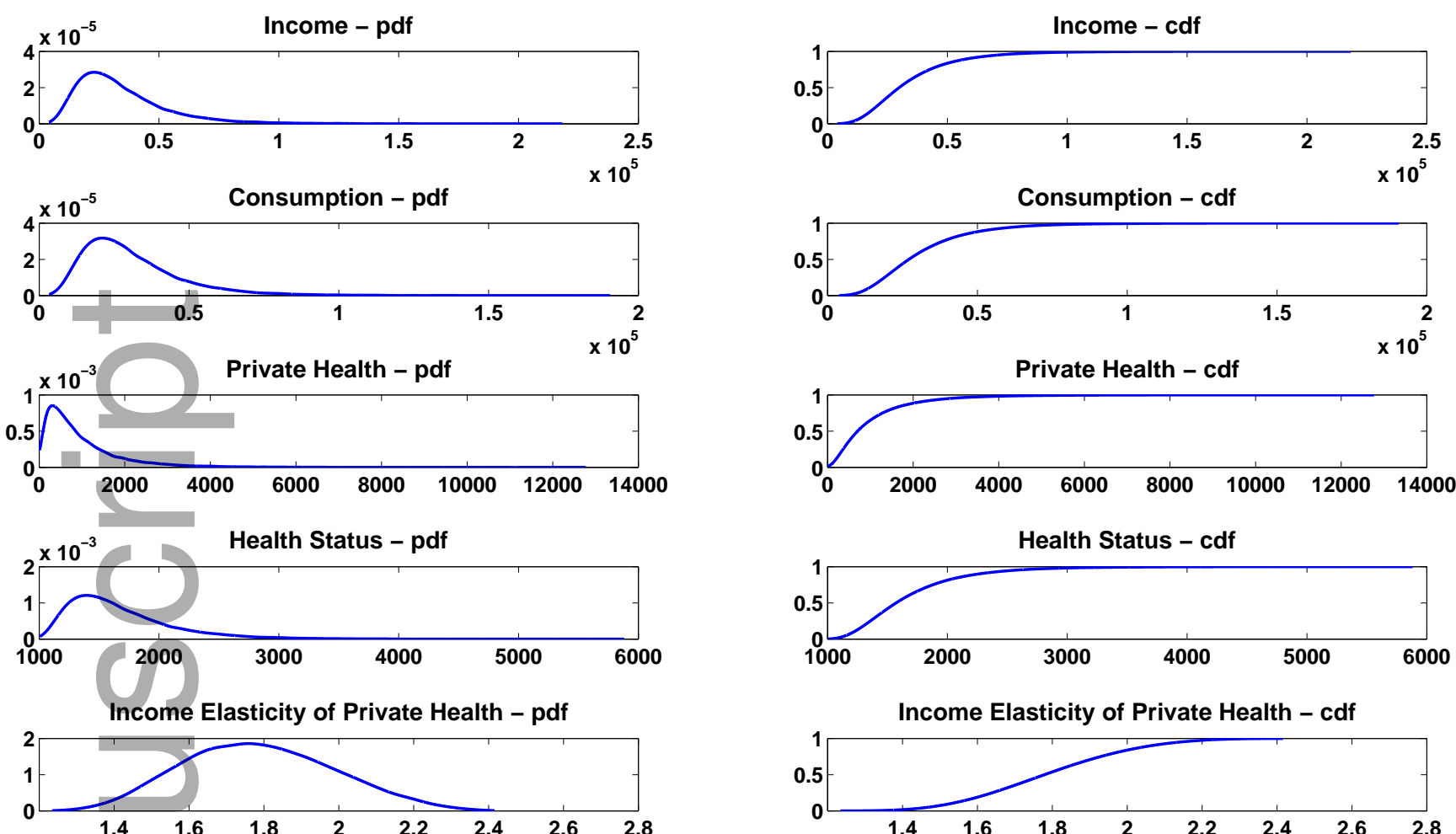

Income Elasticity of Private Health - cdf

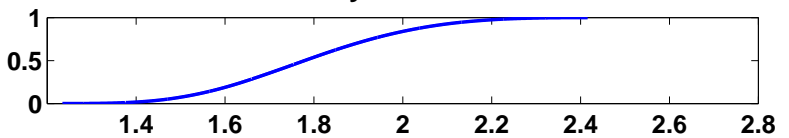

caje_12216_f1.eps

This article is protected by copyright. All rights reserved 


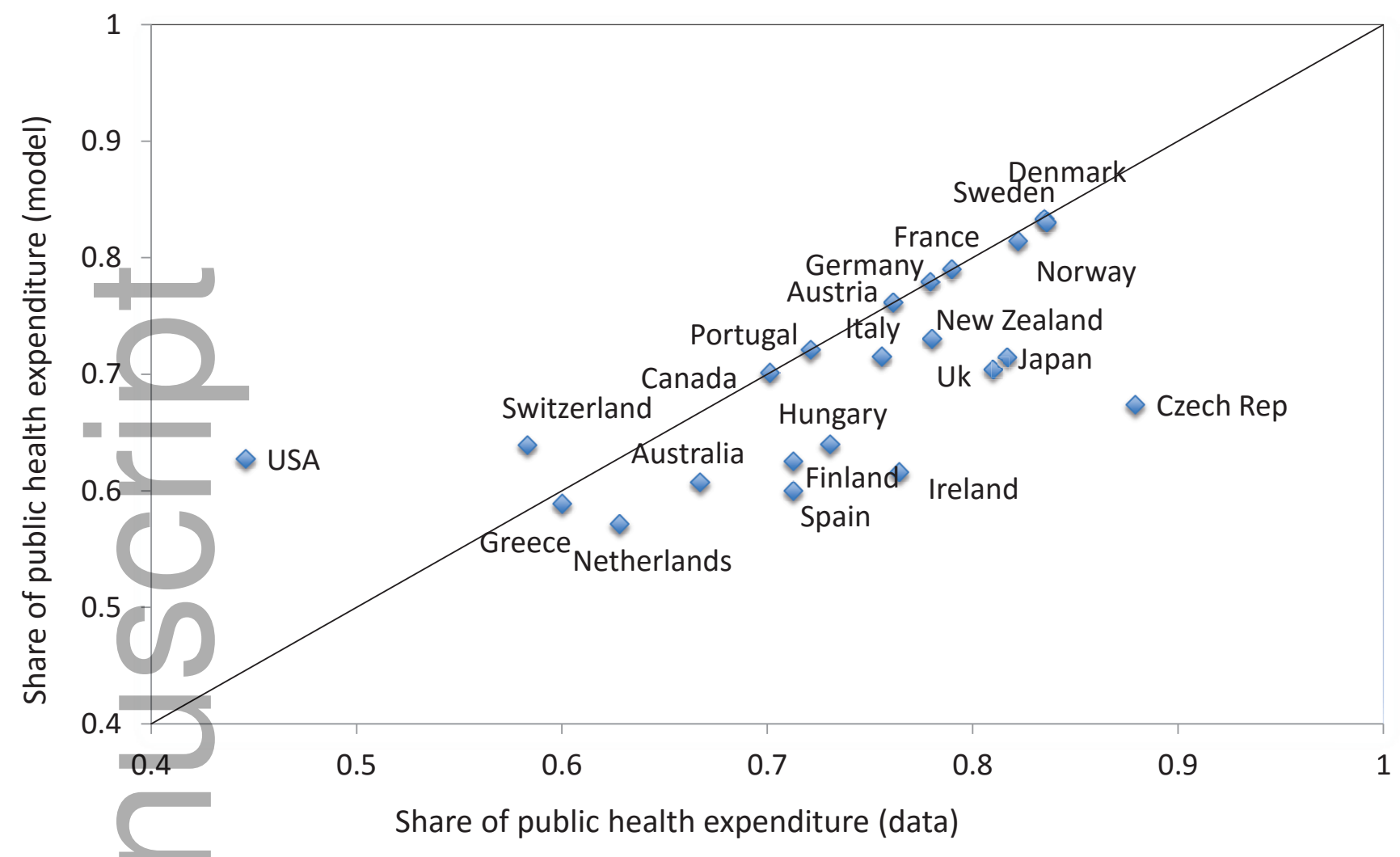

caje_12216_f2.eps

This article is protected by copyright. All rights reserved 


\section{University Library}

\section{- M M N E R VA A gateway to Melbourne's research publications}

Minerva Access is the Institutional Repository of The University of Melbourne

Author/s:

Li, SM;Moslehi, S;Yew, SL

Title:

Public-private mix of health expenditure: A political economy and quantitative analysis

Date:

2016-05-01

Citation:

Li, S. M., Moslehi, S. \& Yew, S. L. (2016). Public-private mix of health expenditure: A political economy and quantitative analysis. CANADIAN JOURNAL OF ECONOMICS-REVUE

CANADIENNE D ECONOMIQUE, 49 (2), pp.834-866. https://doi.org/10.1111/caje.12216.

Persistent Link:

http://hdl.handle.net/11343/291254 